\title{
Can a Clean-Air Heat Pump (CAHP) maintain air purification capability when using
} polluted air for regeneration?

Sheng, Ying; Fang, Lei

Published in:

Building and Environment

Link to article, DOI:

10.1016/j.buildenv.2017.11.038

Publication date:

2018

Document Version

Peer reviewed version

Link back to DTU Orbit

Citation (APA):

Sheng, Y., \& Fang, L. (2018). Can a Clean-Air Heat Pump (CAHP) maintain air purification capability when using polluted air for regeneration? Building and Environment, 128, 170-179.

https://doi.org/10.1016/j.buildenv.2017.11.038

\section{General rights}

Copyright and moral rights for the publications made accessible in the public portal are retained by the authors and/or other copyright owners and it is a condition of accessing publications that users recognise and abide by the legal requirements associated with these rights.

- Users may download and print one copy of any publication from the public portal for the purpose of private study or research.

- You may not further distribute the material or use it for any profit-making activity or commercial gain

- You may freely distribute the URL identifying the publication in the public portal 


\section{Accepted Manuscript}

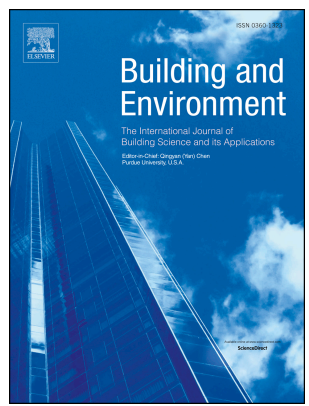

Can a Clean-Air Heat Pump (CAHP) maintain air purification capability when using polluted air for regeneration?

Ying Sheng, Lei Fang

PII: $\quad$ S0360-1323(17)30551-6

DOI: $\quad$ 10.1016/j.buildenv.2017.11.038

Reference: $\quad$ BAE 5191

To appear in: Building and Environment

Received Date: 7 August 2017

Revised Date: 17 November 2017

Accepted Date: 26 November 2017

Please cite this article as: Sheng Y, Fang L, Can a Clean-Air Heat Pump (CAHP) maintain air purification capability when using polluted air for regeneration?, Building and Environment (2017), doi: 10.1016/j.buildenv.2017.11.038.

This is a PDF file of an unedited manuscript that has been accepted for publication. As a service to our customers we are providing this early version of the manuscript. The manuscript will undergo copyediting, typesetting, and review of the resulting proof before it is published in its final form. Please note that during the production process errors may be discovered which could affect the content, and all legal disclaimers that apply to the journal pertain. 


\title{
Can a Clean-Air Heat Pump (CAHP) maintain air purification capability when using polluted air for regeneration?
}

\author{
Ying Sheng ${ }^{1}$, Lei Fang, \\ ${ }^{1}$ Tianjin Key Laboratory of Indoor Air Environmental Quality Control, School of Environmental Science and \\ Engineering, Tianjin University, Tianjin, China \\ ${ }^{2}$ International Centre for Indoor Environment and Energy, Department of Civil Engineering, Technical University of \\ Denmark, Lyngby 2800, Denmark
}

\section{Abstract}

Clean Air Heat Pump (CAHP) was one type of rotary desiccant cooling system which combined a silica gel rotor with a heat pump to achieve air cleaning, dehumidifying and cooling in buildings. Using exhaust air from the conditioned room for regeneration of the silica gel rotor might have an advantage on reducing the regeneration air temperature and further improving the energy performance of the CAHP. However, the exhaust air carried a lot of indoor air pollutants. Whether using exhaust air for the regeneration of the silica gel rotor had an impact on the air cleaning performance of the CAHP was experimentally studied. The results showed that using the air contained acetone or toluene for regeneration reduced the pollutants removal capability of CAHP with a reduction of approx. $10 \%$ in air cleaning efficiency. The energy performance of the CAHP when using exhaust air for regeneration was also evaluated compared with the CAHP with outdoor air for regeneration by means of numerical simulation. The simulated results showed that the energy saving of the CAHP was obvious when using exhaust air for regeneration, regardless of the degradation of indoor air quality. If the same indoor air quality level as that when using outdoor air for regeneration was expected to be maintained, increasing the intake of outdoor air was one possible way but would increase the energy consumption. The increased energy counteracted the reduced energy of using exhaust air for regeneration, and consequently the energy of CAHP was not saved.

Keywords: desiccant wheel; air cleaning; polluted regeneration air

* Corresponding author. Tel.: +45 45254022

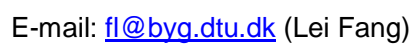

Adress: International Centre for Indoor Environment and Energy, Technical University of Denmark, Building 402, DK-2800, Lyngby, Denmark 


\section{Introduction}

Rotary desiccant cooling (RDC) system can be an attractive alternative to the existing air conditioning system for many advantages such as a large amount of moisture removal, sensible heat and latent load handled independently and a better air quality [1-3]. For a long time, high grade thermal heat (eg. electricity) was used for regenerating the desiccant wheel that led to a substantial energy consumption and restricted the development of RDC system. Afterwards the desiccant cooling system combined with vapor-compression cycle (RDC-VC) was put forward [4-8], which could make full use of both heating and cooling from the condenser and evaporator to provide the thermal energy for desiccant regeneration. One type of RDC-VC system was called Clean-Air Heat Pump (CAHP) which combined a silica gel rotor with a heat pump [9-12]. The recirculation air from the conditioned room was mixed with outdoor air to form process air, which was dehumidified and cleaned by the silica gel rotor, then cooled by the evaporator of the heat pump and delivered to the room. On the other side, the regeneration air taken from outside was heated up by the condenser of the heat pump, and then used to reactive the silica gel rotor. The condensing heat from the heat pump was adequate for reactivating the desiccant wheel without any additional heat. It was found that the CAHP system saved energy in the range of $5 \%$ 59\% in the different summer and winter conditions compared with the traditional vapor compression air conditioning system [12], so that the CAHP system could achieve cooling, heating and ventilation in buildings with less energy consumption.

In addition to the researches on the cooling, dehumidification and energy performance of CAHP system, another feature of air purification potential of the CAHP was found, which mainly due to the extensive adsorption of silica gel desiccant wheel. Early in 1993, Hine et al. [13] studied that the adsorption performance of silica-gel on chemical samples i.e. 1,1,1-trichloroethane, toluene, carbon dioxide, formaldehyde and radon. The results showed that the silica gel was capable of adsorb both water and chemicals. Popescu and Ghosh [14] found that the desiccant material including silica gel, molecular sieve and hydrophobic molecular sieve could remove $40 \%$ for carbon dioxide and $80 \%$ for VOCs selected. The study by Fang et al. [15] showed that more than $80 \%$ sensory air pollutants from building materials, human emissions and dosed pure chemicals were monitored to be removed by a silica gel 
rotor and the percentage dissatisfied with the air quality decreased from $70 \%$ to $20 \%$. Recently Sheng et al. [16] evaluated the perceived indoor air quality by using CAHP. It was found that the percentage dissatisfied was only $5.2 \%$ with the CAHP in operation based on adapted perception assessment.

As aforementioned researches, CAHP achieved cooling, dehumidifying and air cleaning in buildings was based on taking outdoor air as the regeneration air to reactivate the desiccant wheel. However, some researches $[3,17,18]$ indicated that using the exhaust air for regenerating the desiccant wheel had an advantage on reducing the regenerating air temperature since it was dry and hence the vapor pressure difference would be higher. For example, the first rotary desiccant air conditioning cycle, Pennington cycle [19], indicated that the thermal coefficient of performance (COP) and cooling capacity would be increased when using exhaust air for regeneration. In view of this aspect, some rotary desiccant air conditioning cycles adopted exhaust air for regeneration such as the staged regeneration cycle $[20,21]$ and two-stage desiccant cooling system [22]. It seems that using exhaust air for the regeneration of the desiccant rotor can contribute to the energy conservation of the CAHP. However, the exhaust air carries a lot of indoor air pollutants probably from the humans, building materials or electrical machines, which is not clean. It is not certain that the regeneration of a desiccant wheel in the CAHP using polluted air has the same effect of air cleaning as the regeneration of a desiccant wheel using clean outdoor air. Whether the exhaust air has an impact on the air cleaning performance of CAHP should be analysed in detail.

The present study experimentally examined the air cleaning performance of the CAHP system when the polluted air was determined as the regeneration air. Based on the experimental results, the energy performance of the CAHP was simulated by a numerical model, and compared with the situation of the CAHP with outdoor air for regeneration. Finally, a recommendation was provided for the further development of the CAHP.

\section{Experimental Method}

\subsection{Experimental facility}

The experiment was carried out in a test room that equipped with a CAHP system as shown in Fig. 1. A commercially available silica gel rotor produced by Munters was used in the 
experiment and its properties were presented in Table 1. For the vapor-compression cycle, a piston compressor produced by Bitzer was selected with the max power of $2.7 \mathrm{~kW}$. The type of condenser and evaporator was air source chip tubular. The expansion valve with brand of Danfoss was used to adjust the flow rate of the refrigerant. The refrigerant of R134a was adopted in this cycle.

To easily build the experimental conditions, the exhaust air from the room was not directly used for regeneration. Instead another stream of outdoor air was used for regeneration in order to control the type and concentration of pollutants. A humidifier installed was used to make the humidity of regeneration air similar to that of exhaust air.

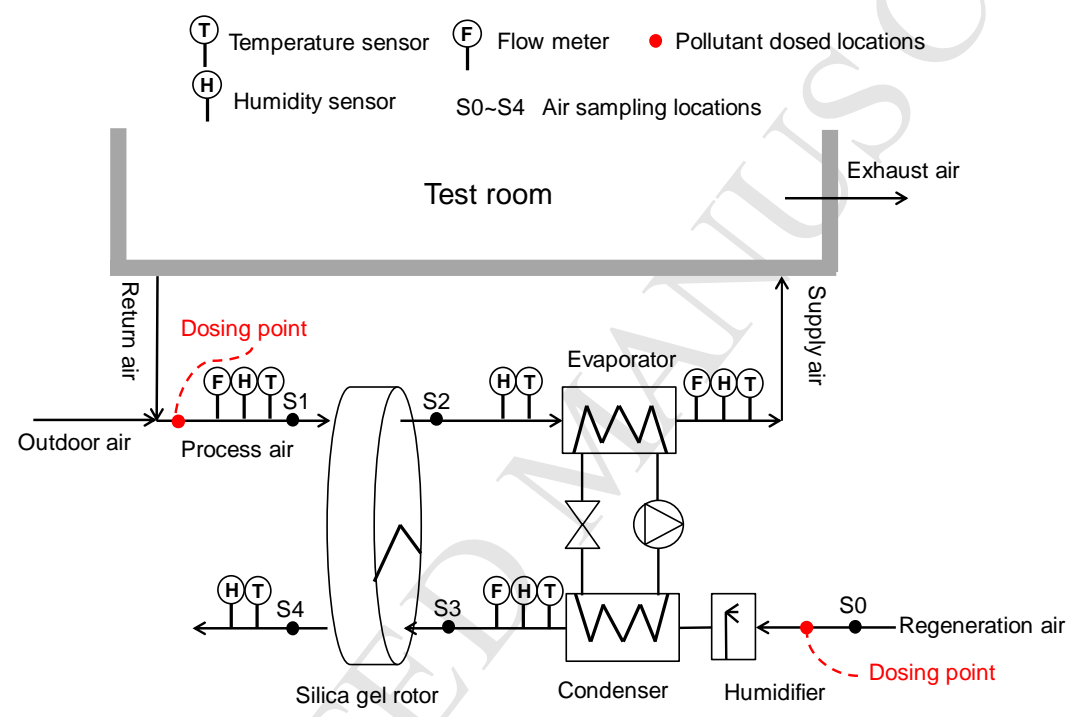

Fig. 1 Experimental facility

\section{Table 1 Specification of silica gel rotor}

\begin{tabular}{lrll}
\hline Thermodynamic properties & & & \\
Specific heat of silica gel $\left[\mathrm{J} /\left(\mathrm{kg}^{\circ} \mathrm{C}\right)\right]$ & 921 & Volume weight $\left(\mathrm{kg} / \mathrm{m}^{3}\right)$ & 200 \\
Specific heat of substrate $\left[\mathrm{J} /\left(\mathrm{kg}^{\circ} \mathrm{C}\right)\right]$ & 900 & Weight percentage of silica gel $(\%)$ & 80 \\
Geometrical parameters & & & 1.9 \\
Radius $(\mathrm{m})$ & 0.225 & Micro duct height $(\mathrm{mm})$ & 3.7 \\
Thickness $(\mathrm{m})$ & 0.2 & Micro duct width $(\mathrm{mm})$ & 0.15 \\
Sectional angel for process air $\left({ }^{\circ}\right)$ & 240 & Total thickness of adsorbent and substrate $(\mathrm{mm})$ & 600 \\
Sectional angel for regeneration air $\left({ }^{\circ}\right)$ & 120 & Pore area $\left(\mathrm{m}^{2} / \mathrm{g}\right)$ & \\
Operating parameters & & & \\
Rotation speed (rounds/h) & 11.6 & & \\
\hline
\end{tabular}


Two air flows of process air and regeneration air entered the wheel:

- process air, dehumidified and cleaned by the silica gel rotor, then cooled by the evaporator of the heat pump and delivered to the room.

- regeneration air, heated by the condenser of the heat pump, and then used to reactivate the silica gel rotor.

\subsection{Pollution sources}

The pure chemicals were selected as the pollution sources, i.e. toluene and acetone. Toluene is nonpolar and non-water-soluble compound which is the common pollutant from the oil paint and adhesive when a building is renovated or decorated [23]. Acetone is polar and water-soluble compound that is normally emitted from the human bio-effluents [24]. These two chemicals can be the representatives of common VOCs existing in the indoor environment and the experimental results can reveal the air purification effect of desiccant wheel for VOCs with different chemical properties. As shown in Fig. 1, the chemicals were dosed in the ventilation ducts at the upstream of process section of silica gel rotor. When the exhaust air was determined for regeneration, the chemical was continuously dosed at the upstream of regeneration side to simulate the concentration of pollutant in the exhaust air. The gas wash bottles were used for dosing the chemicals as shown in Fig. 2. The dosing rate of chemical was controlled by manipulating the airflow rate through the wash bottle. The concentration of the dosed chemical was controlled in the magnitude range of $0-5 \mathrm{ppm}$ that the concentration of each chemical being several times higher than its guideline value for human health [25].

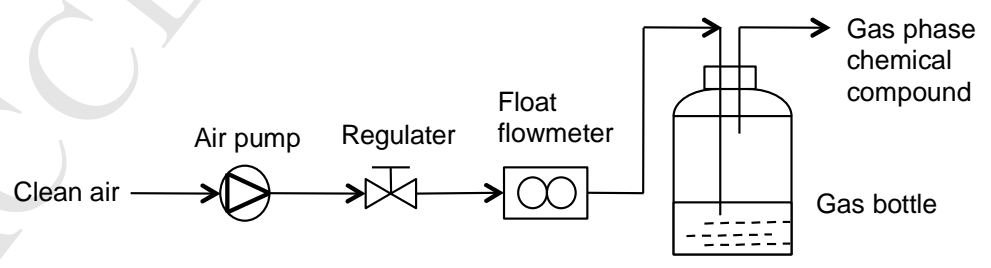

Fig. 2 Schematic diagram of chemicals dosed

\subsection{Physical and chemical measurement}

Physical parameters measured in the CAHP ventilation system included air temperature, air humidity ratio and airflow rates. They were measured continuously throughout each 
exposure in the location as presented in Fig. 1. The specifications of the measuring devices are listed in Table 2.

Table 2 Specifications of the measuring devices in ventilation system

\begin{tabular}{cccc}
\hline Measured parameter & Device & Measuring range & Accuracy \\
\hline & & & $\pm 0.5^{\circ} \mathrm{C}$ at $25^{\circ} \mathrm{C}$, \\
Temperature and & CARELDPD 010000 & $-20^{\circ} \mathrm{C}$ to $70^{\circ} \mathrm{C} /$ & $\pm 0.9^{\circ} \mathrm{C}$ at $-20^{\circ} \mathrm{C}$ to $70^{\circ} \mathrm{C}$; \\
relative humidity & $10 \%$ to $90 \% \mathrm{RH}$ & $\pm 3 \%$ at $25^{\circ} \mathrm{C} / 50 \% \mathrm{RH}$, \\
& & & $\pm 6 \%$ at $-20{ }^{\circ} \mathrm{C}$ to $70^{\circ} \mathrm{C}$. \\
Airflow rate & IRIS & & $\pm 10 \%$ \\
& differential-pressure & $0 \mathrm{~m}^{3} / \mathrm{h}-1260 \mathrm{~m}^{3} / \mathrm{h}$ & \\
\hline
\end{tabular}

Five sampling points for pollutants were installed upstream and downstream of the process side and regeneration side of the wheel as shown in Fig. 1. The sampling points were connected to a photo-acoustic Multi Gas Monitor "INNOVA 1312" by plastic tubes to measure the concentration of the pollutants monitored. INNOVA 1312 was capable of measuring almost any gas that absorbs infrared light and expressed as its toluene equivalent. The accuracies of INNOVA 1312 for measuring concentrations of toluene and acetone was $0.05 \mathrm{ppm}$ and 0.05 ppm respectively after calibration. Its repeatability was $1 \%$ of the measured value in the manufacture's specification. The sampling time and testing time lasted for a total of 40 seconds for each air sample. The concentrations at S0 S4 were measured next to each other in time.

During the experiments, the silica gel rotor was controlled to handle with $260 \mathrm{~L} / \mathrm{s}$ of process air and $144 \mathrm{~L} / \mathrm{s}$ of regeneration air with manual dampers according to the manufacture's instruction. The outdoor air and return air were mixed as the process air. The proportion of outdoor air was $24 \%$. Before dosing and sampling of the pollutants, the experimental conditions listed in Table 3-5 was established in the process and regeneration air flow. The process of equilibration of each thermal condition would nearly take 30 mins. After the thermal conditions reached steady state, pollutants were dosed at the dosing point as the requirements described in the experimental scheme, the concentrations of pollutants at five sampling points were measured by INNOVA 1312 in real time. The concentration of pollutants 
usually took 1-2 hours to reach the steady state, at which the slope of the linear regressions of the concentration of S0-S4 against time was 0 . After the concentration of pollutants reached the steady state, the measurement of pollutant concentration would still last for 1 hour to obtain the average value at the steady state to support the calculation of Eq. (1) to (2). During the whole process of experiments, air temperature, air humidity and air volume at the measuring locations in the ventilation system were measured continuously with an interval of 5 seconds and recorded on a computer by Agilent 34970 data logger. The concentrations of pollutants were measured continuously with an interval of 4 mins and recorded on a computer by INNOVA.

\subsection{Data treatment}

The silica gel rotor was the core component of CAHP for air purification. Since the pollutants removal is in parallel with air moisture removal, the moisture removal efficiency can use for reference to the air cleaning performance of the rotor [26]. Then the single pass air purification efficiency of silica gel rotor $\eta$ represents the air cleaning efficiency of CAHP, which is expressed as the ratio between the real and ideal air cleaning capability of the silica gel rotor:

$$
\eta=\frac{Q_{p r o}\left[\left(c_{S 1}-c_{S 0}\right)-\left(c_{S 2}-c_{S 0}\right)\right]}{Q_{p r o}\left(c_{S 1}-c_{S 0}\right)}=\frac{c_{S 1}-c_{S 2}}{c_{S 1}-c_{S 0}} \times 100 \%
$$

To reveal whether the pollutants were accumulated on the rotor, an index of mass balance $\mathcal{E}$ was also calculated. It represents the ratio between the mass of VOCs desorbed on the regeneration side and the mass of VOCs adsorbed on the process side:

$$
\varepsilon=\frac{Q_{r e g}\left(c_{S 4}-c_{S 3}\right)}{Q_{p r o}\left(c_{S 1}-c_{S 2}\right)} \times 100 \%
$$

-where $c_{S 0}, c_{S 1}, c_{S 2}, c_{S 3}$ and $c_{S 4}$ are the average concentration of pollutants in sample S0 S4, respectively, ppm. $C_{S 0}$ is the average concentration of pollutant in sample S0, ppm. It represents the background pollutant concentration level that is equal to the concentration of pollutants in outdoor air. $Q_{\text {pro }}$ and $Q_{\text {reg }}$ are the process airflow rate and regeneration airflow rate, L/s.

The error analysis carried out in this paper is based on the root of sum square method, 
and it allows the evaluation of the error in results obtained by calculation from measured variables. This method indicates that as the errors are statistically independent, they will partially counteract each other most of the time, such that the square root of the sum of the squares of the individual standard deviation is a more representative value of the overall random standard deviation. The method uses the following relationship:

$\sigma_{y}=\sqrt{\left(\frac{\partial f}{\partial x_{1}}\right) \sigma_{x_{1}}^{2}+\left(\frac{\partial f}{\partial x_{2}}\right) \sigma_{x_{2}}^{2}+\cdots+\left(\frac{\partial f}{\partial x_{n}}\right) \sigma_{x_{n}}^{2}}$

-where $f$ is a function of the independent variable $x_{i}, \sigma_{x_{i}}$ is the standard deviation associated with the variable $X_{i}, y$ is the dependent variable and $\sigma_{y}$ is its standard deviation.

In this work, the performance parameters $(\eta$ and $\varepsilon$ ) described are obtained by calculation from the measured variables (concentration in sample S0 S4, and air volume), each of these measured variable is characterized by a value of standard deviation, then the values of standard deviation of $\eta$ and $\varepsilon$ are obtained.

\subsection{Experimental design and procedure}

Scheme 1: When using polluted air for regeneration, whether the pollutant in the regeneration air would affect the pollutants removal capability of silica gel rotor was firstly investigated. This was accomplished by means of comparative research. The regeneration air temperature was set as $60^{\circ} \mathrm{C}$. After reaching the thermal conditions of process and regeneration air listed in Table 3, the pollutant was dosed at the inlet of the rotor on the process side to simulate the relatively high VOC concentration in the test room, using clean outdoor air for regeneration. When the equilibrium of pollutant concentration was established, the evaluation parameters $(\eta$ and $\varepsilon$ ) were calculated with the average concentrations in sample S0 S4. Then the same pollutant was dosed the regeneration side to simulate using polluted air for regeneration. The concentration of the pollutant in the regeneration air should be similar to that in the process air. When another equilibrium of the concentration of pollutant was established, evaluation parameters were obtained again. Consequently, evaluation parameters obtained in these two scenarios were compared to evaluate the impact of using 


\section{ACCEPTED MANUSCRIPT}

polluted air for regeneration on the air cleaning performance of CAHP. It should be noted that the silica gel rotor would be adequately desorbed after completing each test with a regeneration air temperature of over $100^{\circ} \mathrm{C}$ to avoid any pollutant accumulated on the surface of the wheel, which would be to the detriment of the sequent experiment.

Table 3 Average values of air temperature and humidity at the inlet of silica gel rotor for experimental scheme 1

\begin{tabular}{|c|c|c|c|c|c|}
\hline \multirow{2}{*}{$\begin{array}{c}\text { Pollutant dosed in } \\
\text { Proc. air }\end{array}$} & \multirow{2}{*}{$\begin{array}{c}\text { Pollutant dosed in } \\
\text { Reg. air }\end{array}$} & \multicolumn{2}{|c|}{ Process air } & \multicolumn{2}{|c|}{ Regeneration air } \\
\hline & & $\begin{array}{l}\text { Temp./ } \\
{ }^{\circ} \mathrm{C}\end{array}$ & $\begin{array}{l}\text { Humidity ratio } \\
\qquad(\mathrm{g} / \mathrm{kg})\end{array}$ & $\begin{array}{c}\text { Temp. } \\
{ }^{\circ} \mathrm{C}\end{array}$ & $\begin{array}{l}\text { nidity ratio } \\
(\mathrm{g} / \mathrm{kg})\end{array}$ \\
\hline Acetone & - & 25.0 & 9.78 & 60.2 & 9.82 \\
\hline Acetone & Acetone & 25.0 & 9.78 & 60.2 & 9.82 \\
\hline Toluene & - & 24.1 & 9.32 & 60.3 & 9.40 \\
\hline Toluene & Toluene & 24.1 & 9.32 & 60.3 & 9.40 \\
\hline
\end{tabular}

Scheme 2: Based on the first author's previous study $[9,10]$, the regeneration air temperature of the rotor was generally in the range from 40 to $60^{\circ} \mathrm{C}$ to meet different indoor comfortable requirements. Hence the impact of polluted air with three different temperatures $\left(60,50,40^{\circ} \mathrm{C}\right)$ for regeneration on the performance of CAHP was analysed. For each test with a regeneration air temperature, the equilibrium of thermal conditions of process air and regeneration air (shown in Table 4) were firstly established, and then the pollutant was simultaneously dosed in the process air and regeneration air until the equilibrium of the concentrations of pollutant was established. After completing each test at a regeneration air temperature, the silica gel rotor would also be adequately desorbed. The same procedure was repeated in the scenarios when the regeneration air temperature was $50^{\circ} \mathrm{C}$ and $40^{\circ} \mathrm{C}$. By comparing the parameters of $\eta$ and $\varepsilon$, the impact of regeneration air temperature on air cleaning performance of CAHP using polluted air for regeneration was analysed.

Table 4 Average values of air temperature and humidity at the inlet of silica gel rotor for experimental scheme 2 


\begin{tabular}{|c|c|c|c|c|c|}
\hline \multirow{2}{*}{$\begin{array}{c}\text { Pollutant dosed in } \\
\text { Proc. air }\end{array}$} & \multirow{2}{*}{$\begin{array}{c}\text { Pollutant dosed in } \\
\text { Reg. air }\end{array}$} & \multicolumn{2}{|c|}{ Process air } & \multicolumn{2}{|c|}{ Regeneration air } \\
\hline & & $\begin{array}{l}\text { Temp./ } \\
{ }^{\circ} \mathrm{C}\end{array}$ & $\begin{array}{l}\text { Humidity ratio } \\
\qquad(\mathrm{g} / \mathrm{kg})\end{array}$ & $\begin{array}{l}\text { Temp./ } \\
{ }^{\circ} \mathrm{C}\end{array}$ & $\begin{array}{c}\text { Humidity ratio } \\
(\mathrm{g} / \mathrm{kg})\end{array}$ \\
\hline & & 22.6 & 8.15 & 60.2 & 8.18 \\
\hline \multirow[t]{3}{*}{ Acetone } & Acetone & 22.5 & 8.15 & 50.4 & 8.19 \\
\hline & & 22.6 & 8.16 & 41.3 & 8.18 \\
\hline & & 23.3 & 8.18 & 60.3 & 8.21 \\
\hline \multirow[t]{2}{*}{ Toluene } & Toluene & 23.1 & 8.18 & 50.7 & 8.16 \\
\hline & & 23.3 & 8.20 & 40.0 & 8.23 \\
\hline
\end{tabular}

Scheme 3: The building exhaust of room air in some cases was not centralized or was not located in a convenient location for reactivating the wheel. It was possible that some waste heat carrying with pollutants from other environment would be used to regenerate the wheel. In this occasion, the property of pollutant in the regeneration air was not same as that in the process air. Therefore, the experiment was designed to make the acetone dosed in the process air while the toluene dosed in the regeneration air as indicated in Table 5. Another experimental scenario was to make the acetone and toluene dosed reversedly in two air streams. Finally, the effect of the property of pollutant in the regeneration air on the air cleaning performance of CAHP was analyzed by evaluating the parameters of $\eta$ and $\varepsilon$.

Table 5 Average values of air temperature and humidity at the inlet of silica gel rotor for experimental scheme 3

\begin{tabular}{cccccc}
\hline \multirow{2}{*}{$\begin{array}{c}\text { Pollutant dosed in } \\
\text { Proc. air }\end{array}$} & Pollutant dosed in & \multicolumn{2}{c}{ Process air } & \multicolumn{2}{c}{ Regeneration air } \\
\cline { 3 - 6 } & Reg. air & ${ }^{\circ} \mathrm{C}$ & $(\mathrm{g} / \mathrm{kg})$ & ${ }^{\circ} \mathrm{C}$ & $(\mathrm{g} / \mathrm{kg})$ \\
\hline \multirow{2}{*}{ Acetone } & - & 24.0 & 9.09 & 59.9 & 9.10 \\
& Toluene & 24.0 & 9.09 & 59.9 & 9.10 \\
\multirow{2}{*}{ Toluene } & - & 25.3 & 9.29 & 60.6 & 9.31 \\
& Acetone & 25.3 & 9.29 & 60.6 & 9.31
\end{tabular}

\section{Results of experiments}


The average concentration of pollutants at each sampling point (S0 S4) was the mean value of concentration measured in 1 hour after the equilibrium had been established, which was expressed as mean $\pm S D$ (standard deviation) in the figures. According to the theory of error analysis stated in this study, the error of evaluation parameters $\eta$ and $\varepsilon$ were calculated and the specific values are shown as mean \pm SD. It is found that the standard deviation values obtained for the calculated parameters are as follows: $2 \% \sim 6 \%$ for $\eta$ and $6 \% \sim 15 \%$ for $\mathcal{E}$ in these experimental conditions provided.

\subsection{Effect of polluted air for regeneration on air cleaning of CAHP}

The results of gas-phase pollutants removal capacity of CAHP when the same pollutant contained in the regeneration air or not are shown in Fig. 3 and Fig. 4. It is found in Fig. 3 that the concentration of acetone in the process air was significantly reduced $(\mathrm{S} 1 \rightarrow \mathrm{S} 2)$ after being processed by CAHP when outdoor air was used for regeneration, with an air cleaning efficiency $\eta$ of $69.7 \%$ based on the calculation of Eq. (1). The adsorbed acetone by the rotor was also effectively desorbed $(\mathrm{S} 3 \rightarrow \mathrm{S} 4)$ at $\mathrm{T}_{\text {reg }}=60^{\circ} \mathrm{C}$ with an index of mass balance $\varepsilon$ of 96.0\%. After dosing acetone in the regeneration air with a similar dosing rate of acetone dosed in the process air, the concentration of acetone after the rotor in the process side (S2) was continuously increased until another new equilibrium of concentration was established. Based on the calculation of $\eta$ and $\varepsilon$ using the average concentrations of acetone (S0 S4), it is found that air cleaning efficiency $\eta$ was reduced from $69.7 \%$ to $59.4 \%$ and mass balance $\varepsilon$ was also reduced from $96.0 \%$ to $80.2 \%$. It was probably because that in presence of higher acetone content in the regeneration air, there was a minor difference of acetone content partial pressure between regeneration air and silica gel surface, and this determined a weaker diffusion of the acetone from the surface to the air and finally obtained a lower $\mathcal{E}$. This effect reduced the adsorption space of silica gel and then less pollutants can be removed from the process air, which made the value of $\eta$ reduced.

Fig. 4 shows the results that toluene was the pollutant when the regeneration air temperature was $60^{\circ} \mathrm{C}$. Toluene is a nonpolar, non-water soluble compound, however silica gel has a strong affinity for polar molecules, which means that the silica gel rotor will not remove toluene as effective as acetone. This was testified by comparing the results shown in Fig. 3 
and Fig.4. Even so, more than $50 \%$ of toluene can still be removed with a regeneration temperature of $60^{\circ} \mathrm{C}$ when using outdoor air for regeneration. When toluene was dosed in the regeneration air, due to the same reason explained for acetone as the pollutant, the air cleaning efficiency of CAHP was reduced from $52 \%$ to $43.2 \%$ and the index of mass balance $\mathcal{E}$ was reduced from $90.0 \%$ to $78.3 \%$.

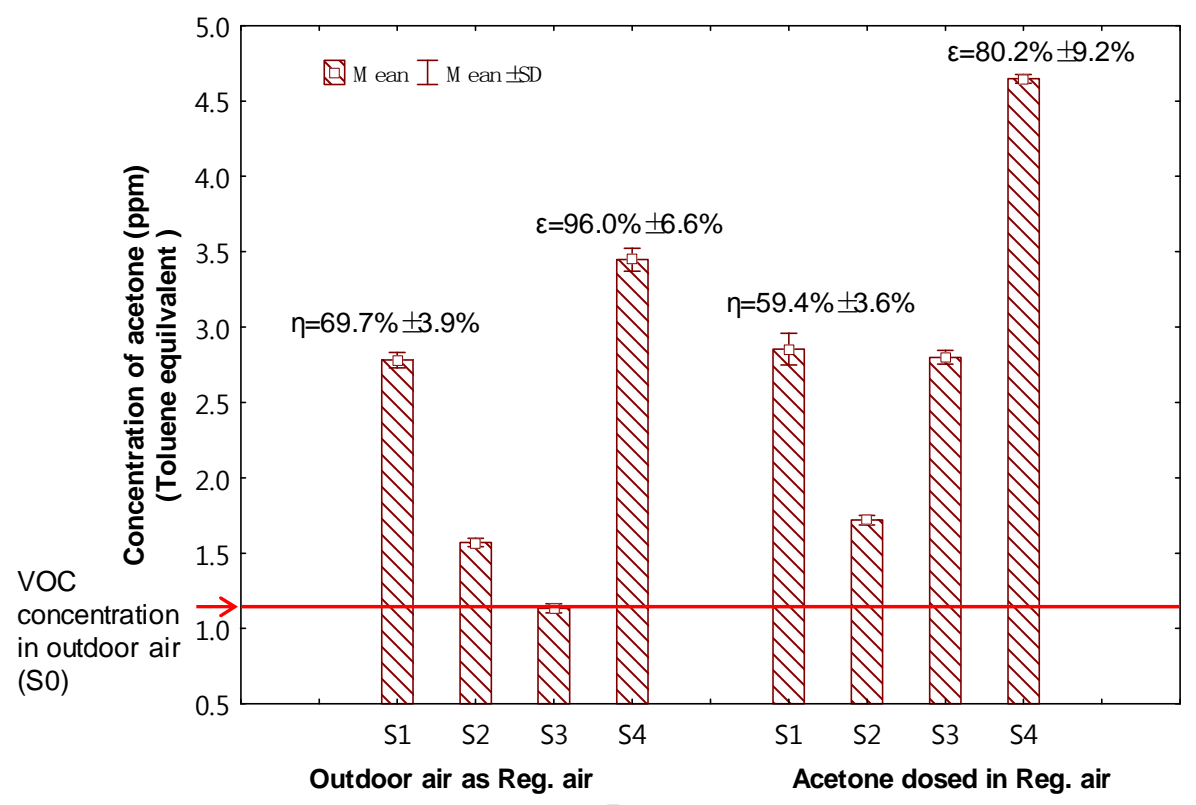

Fig. 3 Average concentration of acetone upstream and downstream of the process and regeneration side when $\mathrm{T}_{\text {reg }}=60^{\circ} \mathrm{C}$

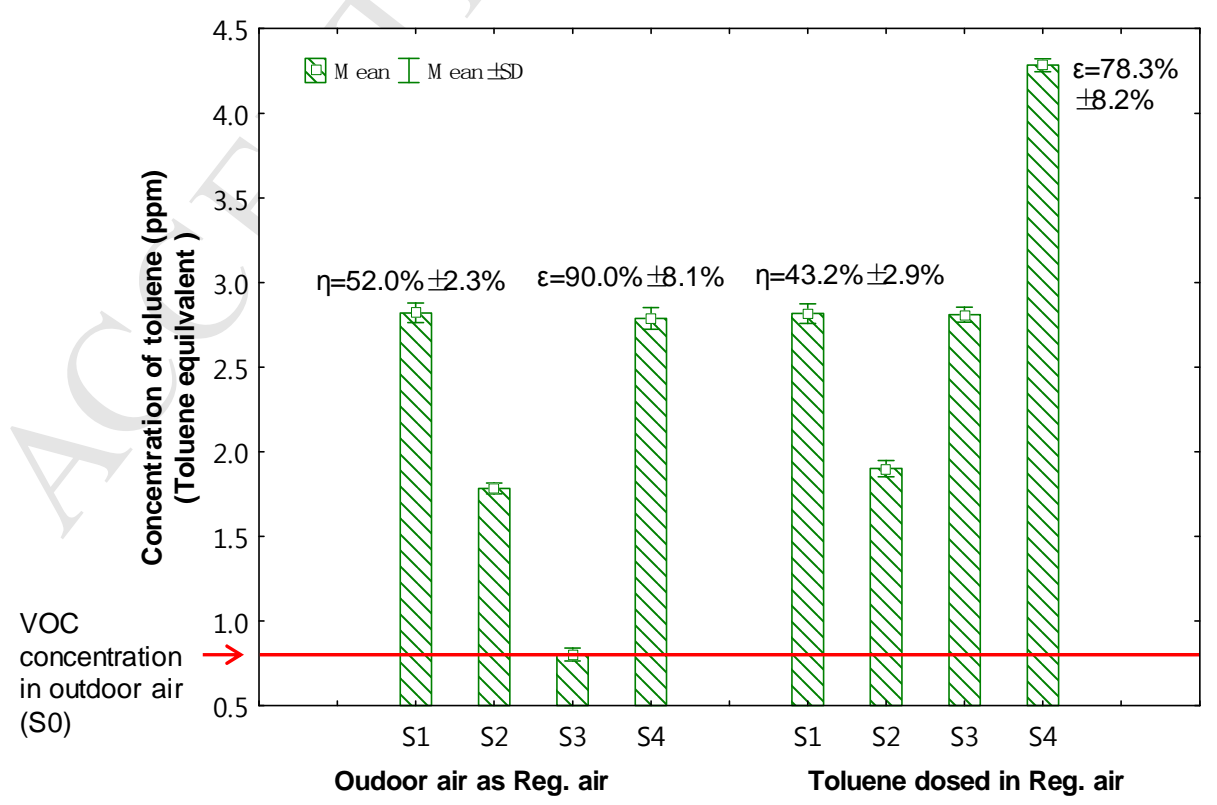

Fig. 4 Average concentration of toluene upstream and downstream of the process 


\section{ACCEPTED MANUSCRIPT}

\section{and regeneration side when $\mathrm{T}_{\text {reg }}=60^{\circ} \mathrm{C}$}

3.2 Effect of polluted regeneration air with different temperature on air cleaning of CAHP

Fig. 5 shows the concentration of acetone upstream and downstream of the process and regeneration side at different regeneration air temperatures for the silica gel rotor, expressed by mean $\pm S D$. It is found that the higher regeneration air temperature for the rotor, the higher air cleaning efficiency obtained. The rise in regeneration air temperature caused an increase in the surface temperature of silica gel, and thus a major difference of acetone partial pressure between regeneration air and silica gel surface. Therefore, acetone adsorbed was easily fled away from the rotor surface, which made adsorption sites unoccupied for the further adsorption with the rotation of the rotor and determined a higher air cleaning efficiency. Compared with the condition $\mathrm{T}_{\text {reg }}=60^{\circ} \mathrm{C}$, although the purification capability of CAHP was significantly reduced at the temperature of $40^{\circ} \mathrm{C}$, it was still over $50 \%$. Since the regeneration air temperature was too low to make the wheel reactivated adequately, the mass balance index was reduced to $62.9 \%$. Fig. 6 gives the results when using toluene instead of acetone as the pollutant. The same trend of experimental results was observed for the measured data of toluene, namely higher regeneration air temperature led to a higher $\eta$ and $\varepsilon$. However, compared to the acetone removal capability of CAHP, the air cleaning effect for toluene was less effective. The air cleaning efficiency $\eta$ was only $34.7 \%$ and the mass balance $\varepsilon$ was accordingly $64.8 \%$ when the regeneration air temperature was $40^{\circ} \mathrm{C}$. 


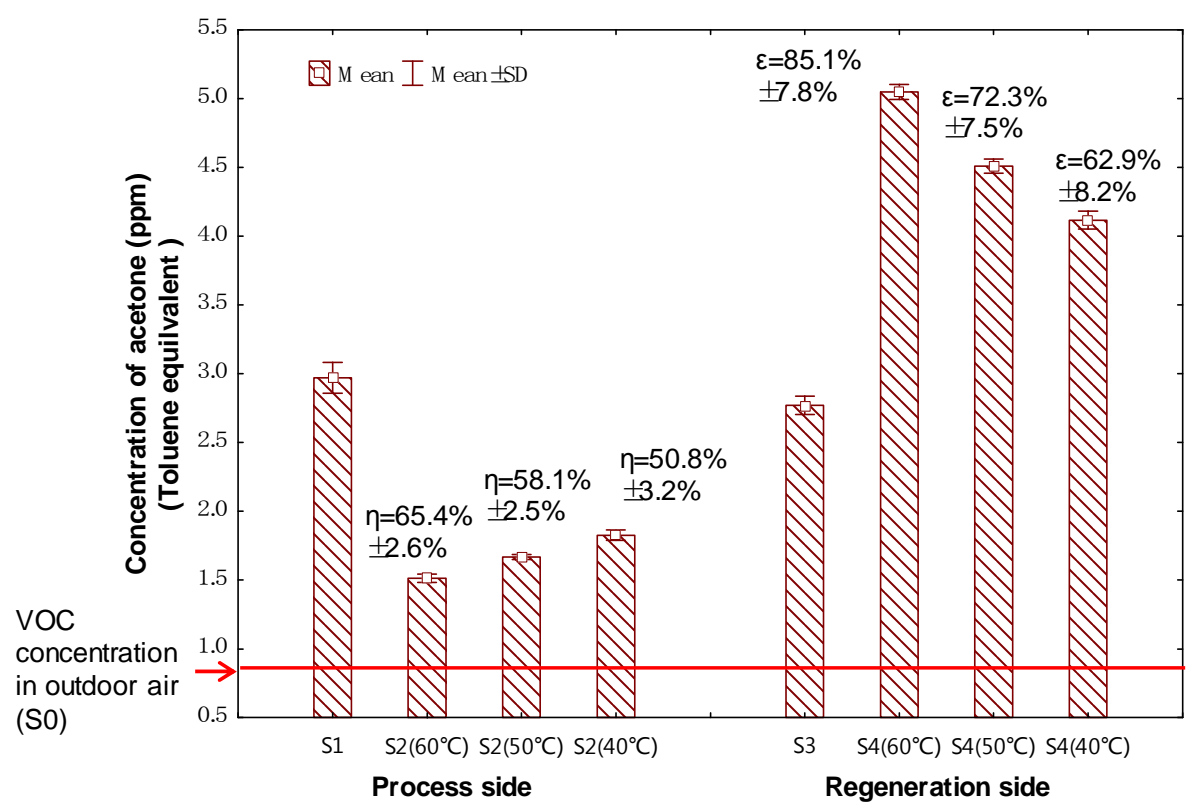

Fig.5 Average concentration of acetone upstream and downstream of the process and regeneration side at the regeneration temperature of $40,50,60^{\circ} \mathrm{C}$

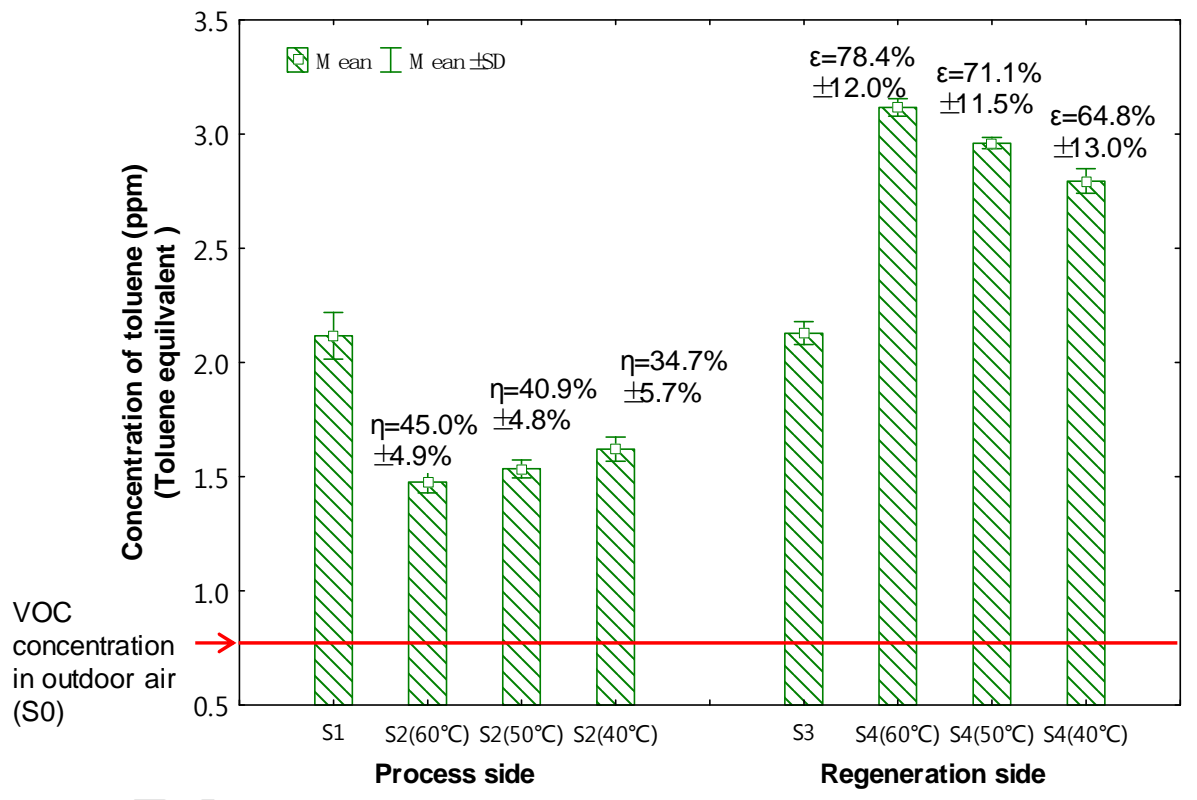

Fig.6 Average concentration of toluene upstream and downstream of the process and regeneration side at the regeneration temperature of $40,50,60^{\circ} \mathrm{C}$

\subsection{Effect of property of pollutant in the regeneration air on air cleaning of CAHP}

The acetone removal capability of CAHP was tested when using outdoor air or the air with toluene for regeneration and the results are compared in Fig. 7. Using the air carrying toluene to reactivate the rotor, acetone was removed in the process air by the silica gel rotor and 
rejected with toluene after regeneration. Compared with using outdoor air for regeneration, the air cleaning efficiency $\eta$ was reduced by $10.6 \%$ and the mass balance $\mathcal{\varepsilon}$ was reduced by $8.9 \%$. However, the extent of reduction of $\eta$ was not significantly different from the results shown in Fig. 3 ( $\eta$ has a reduction of $10.3 \%$ ) in the occasion of using the air containing acetone for regeneration. Fig. 8 shows that the results of the toluene was removed by the CAHP with acetone contained in the regeneration air and the similar variation of $\eta$ and $\varepsilon$ were observed. The property of pollutant in the regeneration air would not have a significant impact on the extent of reduction of evaluation parameters. Therefore, it is indicated that when using CAHP to remove the target pollutant in the process air, no matter whether the same pollutant or a different type of pollutant contained in the regeneration air, CAHP had a very similar removal capability for target pollutant.

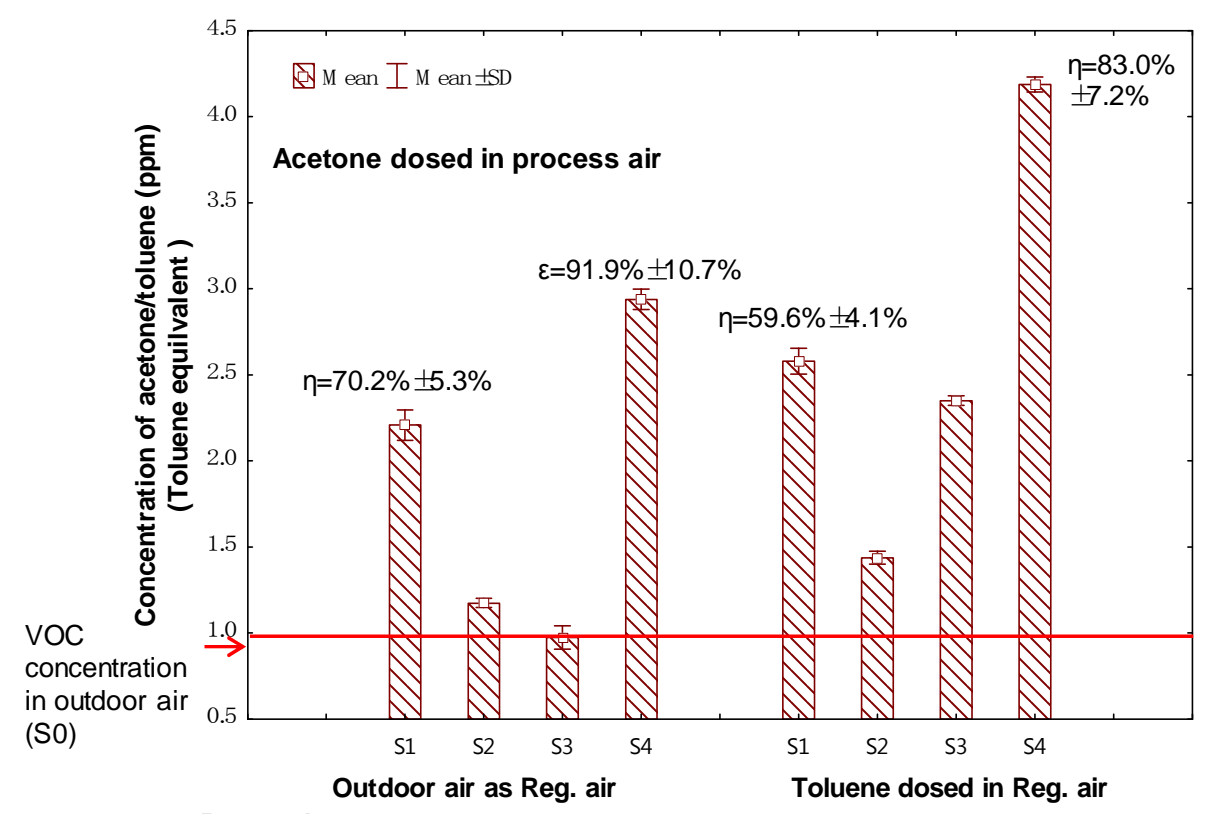

Fig. 7 Average concentration of acetone/toluene when toluene determined as pollutant in the regeneration air at $\mathrm{T}_{\text {reg }}=60^{\circ} \mathrm{C}$ 


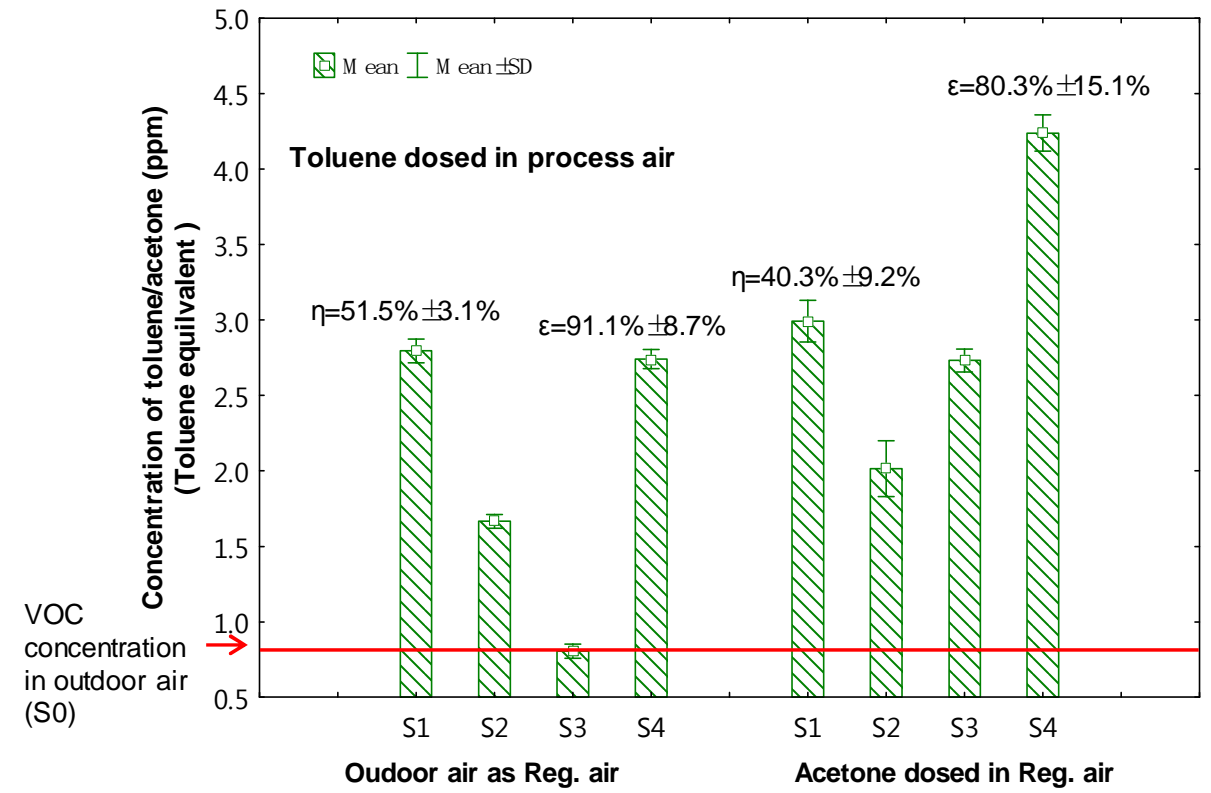

Fig. 8 Average concentration of toluene/acetone when acetone determined as pollutant in the regeneration air at $T_{\text {reg }}=60^{\circ} \mathrm{C}$

\section{Energy performance of CAHP using exhaust air for regeneration}

The previous studies [19-22] indicated that using exhaust air to regenerate the rotor in the desiccant cooling system improved the energy performance and saved energy. However, the experimental results in this study indicated that using polluted air for regeneration indeed affected the air cleaning performance of CAHP, which would lead to an indoor environment degradation. If the same level of indoor air quality is expected to be maintained, one possible solution is to increase the intake of outdoor fresh air, but this will consume energy to deal with the increased thermal and latent load. Therefore, the lost energy to keep the indoor air quality may counteract the saved energy when using exhaust air for regeneration. Whether the energy consumption of CAHP is reduced or not was analyzed by means of theoretical calculation.

To predict the energy performance of CAHP under different regeneration conditions, a theoretical model for the CAHP had been built. The theoretical model consisted of two parts, the silica gel rotor sub-model and heat pump sub-model. The silica gel rotor sub-model was used to simulate heat and moisture transfer in the silica gel rotor. With the sub-model, setting the airflow rates, thermal conditions of indoor/ outdoor air and the target supply air humidity ratio as input parameters, the temperature of dehumidified-cleaned air coming out from the 
silica gel rotor and the required regeneration air temperature could be calculated. With the simulation results from the silica gel rotor sub-model, setting the target supply air temperature as another input parameter, the energy consumption of the heat pump could be calculated by the heat pump sub-model. Thus, the energy performance of the CAHP could be simulated with the two sub-models. More information of the theoretical model can be find in the authors previous work [11].

Before calculating the energy consumption, comparing with outdoor air for regeneration, the reduction of air cleaning efficiency $\eta$ of CAHP was set as $10 \%$ when using exhaust air for regeneration. If the regeneration air temperature was reduced by $1{ }^{\circ} \mathrm{C}$, the air cleaning efficiency of CAHP would be further reduced by $1 \%$. For example, the reduction of $\eta$ was $12 \%$ with exhaust air for regeneration at $58^{\circ} \mathrm{C}$ comparing to $\eta$ with outdoor air for regeneration at $60^{\circ} \mathrm{C}$

To maintain the same concentration of pollutants in the indoor air as that achieved by CAHP with outdoor air for regeneration, some outdoor air would be supplemented to the test room. An index of Clean Air Deliver Rate (CADR) was used to calculate the increased outdoor air volume when using exhaust air for regeneration to maintain the same indoor air quality. CADR was used to express the air cleaning effect of the CAHP system as being equivalent to an additional airflow of fresh air to the test room. It can be expressed as in the following equation.

$$
C A D R=Q_{o}\left(\frac{c_{\text {none }}}{c_{\text {CAHP }}}-1\right)
$$

- where CADR [27] is clean air delivery rate of the CAHP in air change volume per hour, $\mathrm{L} / \mathrm{s} ; Q_{0}$ is outdoor airflow rate, equals to $62.4 \mathrm{~L} / \mathrm{s}$ as designed, $c_{\text {none }}$ is concentration of pollutants of indoor air in the test room with CAHP turned off (ppm) and $c_{C A H P}$ is concentration of pollutants of indoor air with CAHP in operation (ppm). Here the concentration of pollutants in the supply air is determined to represent the concentration of pollutants of indoor air.

When the CAHP was turned on with outdoor air for regeneration, $c_{C A H P}$ was recorded as 
$c_{2}$, its value was equal to $(1-\eta) c_{\text {none }}$ based on the Eq. (1) when the concentration of pollutants in the outdoor air was assumed as 0 , namely the concentration of pollutants in the supply air ( $\eta$ was the air cleaning efficiency of the CAHP). When the CAHP was turned on with exhaust air for regeneration, $c_{C A H P}$ was recorded as $c_{3}$, which was equal to $[1-(\eta-\mathrm{x})] c_{\text {none }}(x$ was the reduction of $\eta$ ). The value of $\eta$ was based on the experimental results, namely $\eta$ equaled to $50 \%, 60 \%, 70 \%$ at the regeneration air temperature of $40,50,60 \square$. Therefore, the difference of intake of outdoor air $\Delta Q$ under the conditions with CAHP using outdoor air and exhaust air for regeneration was calculated as:

$\Delta Q=Q_{0}\left(\frac{c_{\text {none }}}{c_{2}}-1\right)-Q_{0}\left(\frac{c_{\text {none }}}{c_{3}}-1\right)=\left[\frac{1}{1-\eta}-\frac{1}{[1-(\eta-x)]}\right] Q_{0}$

Then the total intake of outdoor air to the test room was increased to $Q_{0}+\Delta Q$ and the total air volume ventilated the test room would be increased to $Q_{p r o}+\Delta Q$. Accordingly the outdoor air ratio (OAR) of total air volume of the test room can be calculated as:

$$
O A R=\frac{Q_{0}+\Delta Q}{Q_{\text {pro }}+\Delta Q} \times 100 \%
$$

This increased outdoor air ratio would change the thermal-hygro conditions of process air before the rotor, which would lead to an increase in the thermal and moisture load handled by the CAHP. To ensure the intended conditions of supply air, the regeneration air temperature would further be increased. In this study, the target hygro-thermal conditions of supply air were set as $20 \square$ and $8.85 \mathrm{~g} / \mathrm{kg}$, which balanced the thermal and moisture load of the test room. The indoor thermal environment was set as $25 \square$ with $9.7 \mathrm{~g} / \mathrm{kg}$ moisture. The energy consumption of CAHP would be calculated under two typical outdoor climates in the summer, namely a mild climate zone with hygro-thermal condition of $25 \square / 11.5 \mathrm{~g} / \mathrm{kg}$ and an extremely hot humid climate zone with hygro-thermal condition of $28.5 \square / 18.5 \mathrm{~g} / \mathrm{kg}$. Refrigerant R134a was used in the heat pump sub-model for energy performance analyzing. The energy consumed by CAHP was the electrical power to drive the compressor of the heat pump and fans. In this study, the electricity input for fans was ignored.

Inputting the parameters of air flow rate, air temperature and humidity of the process air 
before rotor as well as the intended air temperature and humidity of supply air, and the air flow rate, air humidity of regeneration air to the theoretical model of CAHP, the energy performance of CAHP can be simulated and analyzed. The simulation results of energy consumptions of the CAHP operated under different outdoor climates are summarized in Table 6.

In the mild climate, when the CAHP was turned on with outdoor air for regeneration, due to the high air humidity ratio of regeneration air $(11.5 \mathrm{~g} / \mathrm{kg})$, the regeneration air temperature was calculated as $40 \square$ to obtain the intended supply air conditions, and the energy consumption was $0.59 \mathrm{~kW}$. If the exhaust air with a low air humidity of $9.7 \mathrm{~g} / \mathrm{kg}$ substituted outdoor air for regeneration, the regeneration air temperature was reduced to $37^{\circ} \mathrm{C}$ which reduced the condensing temperature of heat pump, and then the energy consumption was reduced to $0.50 \mathrm{~kW}$ which was saved by $15.1 \%$. In this case, although the energy was saved, the indoor air quality was worsened due to the reduction of air cleaning efficiency of CAHP. To maintain the indoor air quality, additional outdoor air was supplemented and the outdoor air ratio was calculated from $24 \%$ to $43 \%$ based on the Eq. (4 6). To ensure the target supply air conditions, the regeneration air temperature was kept as $40^{\circ} \mathrm{C}$ and more energy was consumed to handle with the increased heat and latent load. As a result, the energy was not saved compared with the condition of using outdoor air for regeneration.

In the extreme hot humid climate, to acquire the desired supply air conditions, the regeneration air temperature was high to $61^{\circ} \mathrm{C}$ when the CAHP used outdoor air for regeneration with an air humidity of $18.5 \mathrm{~g} / \mathrm{kg}$. Using exhaust air (air humidity of $9.7 \mathrm{~g} / \mathrm{kg}$ ) substituting outdoor air for regeneration made the regeneration air temperature reduced to $51^{\circ} \mathrm{C}$, which made the condensing temperature of heat pump greatly reduced and accordingly the energy was significantly saved by $32.5 \%$. If taking the effect of exhaust air on air cleaning performance of CAHP into consideration, to keep the same concentration of pollutants in the indoor air, the outdoor air ratio was increased to $37 \%$. To handle the increased the heat and latent load, the regeneration air temperature was back toward to $60^{\circ} \mathrm{C}$ and more energy was consumed. The energy was lost by $9.4 \%$ compared to the condition of CAHP using outdoor air for regeneration. 


\section{ACCEPTED MANUSCRIPT}

It is found that if the CAHP was operated as an air conditioner with air purification as an affiliated function, using exhaust air to regenerate the rotor can significantly improve the energy performance of CAHP, especially in the hot humid climate zones. From the point of indoor air quality view, the variation of perceived indoor air quality should be evaluated by a panel of human subjects. If this variation of air quality cannot be precepted, using exhaust air for regeneration of CAHP was recommended from the energy point of view. If the CAHP was regarded as a purifier, the increased energy for keeping the indoor air quality was more than the reduced energy of using exhaust air for regeneration, and consequently the energy performance of CAHP was not improved. Therefore, if the concentration of pollutants in the indoor air was required to be strictly controlled, it is recommended that using outdoor air for the regeneration of the rotor and installing pollutant sensors to provide effective signal to control the operation of CAHP. 
Table 6 Operating conditions and simulation results of energy performance of CAHP system

\begin{tabular}{|c|c|c|c|c|c|c|c|c|c|c|c|c|c|c|c|}
\hline \multirow{2}{*}{ No. } & \multicolumn{2}{|c|}{ indoor air } & \multicolumn{3}{|c|}{ Outdoor air } & \multicolumn{2}{|c|}{$\begin{array}{l}\text { Pro. air before } \\
\text { rotor }\end{array}$} & \multicolumn{2}{|c|}{ Pro. air after rotor } & \multicolumn{2}{|c|}{$\begin{array}{l}\text { Reg. air before } \\
\text { rotor }\end{array}$} & \multicolumn{2}{|c|}{ Supply air } & \multicolumn{2}{|c|}{$\begin{array}{l}\text { Simulation } \\
\text { results }\end{array}$} \\
\hline & $\begin{array}{l}\text { Temp. } \\
\left({ }^{\circ} \mathrm{C}\right)\end{array}$ & $\begin{array}{l}\text { Humd. } \\
(\mathrm{g} / \mathrm{kg})\end{array}$ & $\begin{array}{c}\text { Temp. } \\
\left({ }^{\circ} \mathrm{C}\right)\end{array}$ & $\begin{array}{l}\text { Humd. } \\
(\mathrm{g} / \mathrm{kg})\end{array}$ & $\begin{array}{l}\text { outdoor } \\
\text { air ratio } \\
\text { (\%) }\end{array}$ & $\begin{array}{c}\text { Temp. } \\
\left({ }^{\circ} \mathrm{C}\right)\end{array}$ & $\begin{array}{l}\text { Humd. } \\
(\mathrm{g} / \mathrm{kg})\end{array}$ & $\begin{array}{l}\text { Temp. } \\
\left({ }^{\circ} \mathrm{C}\right)\end{array}$ & $\begin{array}{l}\text { Humd. } \\
(\mathrm{g} / \mathrm{kg})\end{array}$ & $\begin{array}{l}\text { Temp. } \\
\left({ }^{\circ} \mathrm{C}\right)\end{array}$ & $\begin{array}{l}\text { Humd. } \\
(\mathrm{g} / \mathrm{kg})\end{array}$ & $\begin{array}{l}\text { Temp. } \\
\left({ }^{\circ} \mathrm{C}\right)\end{array}$ & $\begin{array}{l}\text { Humd. } \\
(\mathrm{g} / \mathrm{kg})\end{array}$ & $\begin{array}{c}\mathrm{E} \\
(\mathrm{kW})\end{array}$ & $\begin{array}{l}\text { Energy } \\
\text { saving } \\
\text { rate }(\%)\end{array}$ \\
\hline 1 & \multirow{6}{*}{25.0} & \multirow{6}{*}{9.70} & & & $24 \%$ & 25.00 & 10.13 & 28.93 & 8.87 & 40.00 & 11.50 & 20.00 & 8.87 & $0.59^{a}$ & - \\
\hline 2 & & & 25.00 & 11.50 & $24 \%$ & 25.00 & 10.13 & 29.60 & 8.89 & 37.00 & 9.70 & 20.00 & 8.89 & $0.50^{\mathrm{b}}$ & $15.1 \%$ \\
\hline 3 & & & & & $43 \%$ & 25.00 & 10.47 & 29.60 & 8.87 & 40.00 & 9.70 & 20.00 & 8.87 & $0.63^{c}$ & $-7.5 \%$ \\
\hline 4 & & & & & $24 \%$ & 25.72 & 11.81 & 34.93 & 8.86 & 61.00 & 18.50 & 20.00 & 8.86 & $2.02^{d}$ & - \\
\hline 5 & & & 28.50 & 18.50 & $24 \%$ & 25.72 & 11.81 & 33.90 & 8.88 & 51.00 & 9.70 & 20.00 & 8.88 & $1.36^{\mathrm{e}}$ & $32.5 \%$ \\
\hline 6 & & & & & $37 \%$ & 26.08 & 12.87 & 37.40 & 8.93 & 60.00 & 9.70 & 20.00 & 8.93 & $2.21^{\dagger}$ & $-9.4 \%$ \\
\hline
\end{tabular}

Note: The air volume of process air and regeneration air are kept constant of 260 and $144 \mathrm{~L} / \mathrm{s}$.

Values of No.1 No.3 show the simulation results with CAHP operated in the mild climate and Values of No.4 No.6 show the results with CAHP operated in the hot and humid climate.

${ }^{a, c}$ Energy consumption of CAHP using outdoor air for rotor regeneration;

${ }^{b, e}$ Energy consumption of CAHP using exhaust air for rotor regeneration regardless of the degradation of indoor air quality;

c,f Energy consumption of CAHP using exhaust air for rotor regeneration taking the degradation of indoor air quality into consideration. 


\section{Discussion}

The VOC concentrations in the experiments were high, generally 10 times its guideline [25] value for human health, which takes the accuracy of INNOVA into consideration and makes the concentration variation of pollutant upstream and downstream of the process and regeneration air easily observed. Due to this high concentration of VOC, the air cleaning efficiency was only $70 \%$ at the regeneration temperature of $60^{\circ} \mathrm{C}$ in this study, which was not high up to $90 \%$ in our previous study of [15] when testing the air purification performance of silica gel rotor. The high moisture in the process air in this study (the relative humidity was nearly $50 \%$ ) can also aggravate the adsorption competition between water vapour and VOC and consequently reduce the VOC removal efficiency. However, the object of this study is not to identify the specific quantity but reveal the trends under different conditions of regeneration air. The variation trends on air cleaning performance of CAHP was therefore not influenced by these specific values.

From the observation and calculation in this study, the acetone or toluene adsorbed were removed from the rotor after regeneration with an index of mass balance was in the range from 60 to $96 \%$. A great concern may be risen that part of VOC will be continuously accumulated until the saturation of rotor. In order to get a clear understanding of the regeneration, a 10-h test of toluene removal at the regeneration air temperature of $50^{\circ} \mathrm{C}$ had been conducted and analysed, and the results are shown in Fig. 9. At 11:00, toluene was dosed at the inlet of desiccant wheel on the process side and it was effectively removed with time using outdoor air for regeneration until approx. 12:00 to reach a steady state. Then toluene was dosed in regeneration air at 14:00 to simulate using polluted air for regeneration, which led to a significant reduction of mass balance. The mass balance was firstly dropped and then risen and finally kept constant of approx. $70 \%$ and there was no reduction trend of mass balance observed until the end of this test. This test indicated that the operation of the desiccant rotor was in a dynamic balance after reaching a steady state and the rotor would not be saturated. However, the results are limited to the specific conditions analysed in the present study. The long period experiment for CAHP when using polluted air for regeneration, at least a few days, should be further studied to verify this conclusion. 


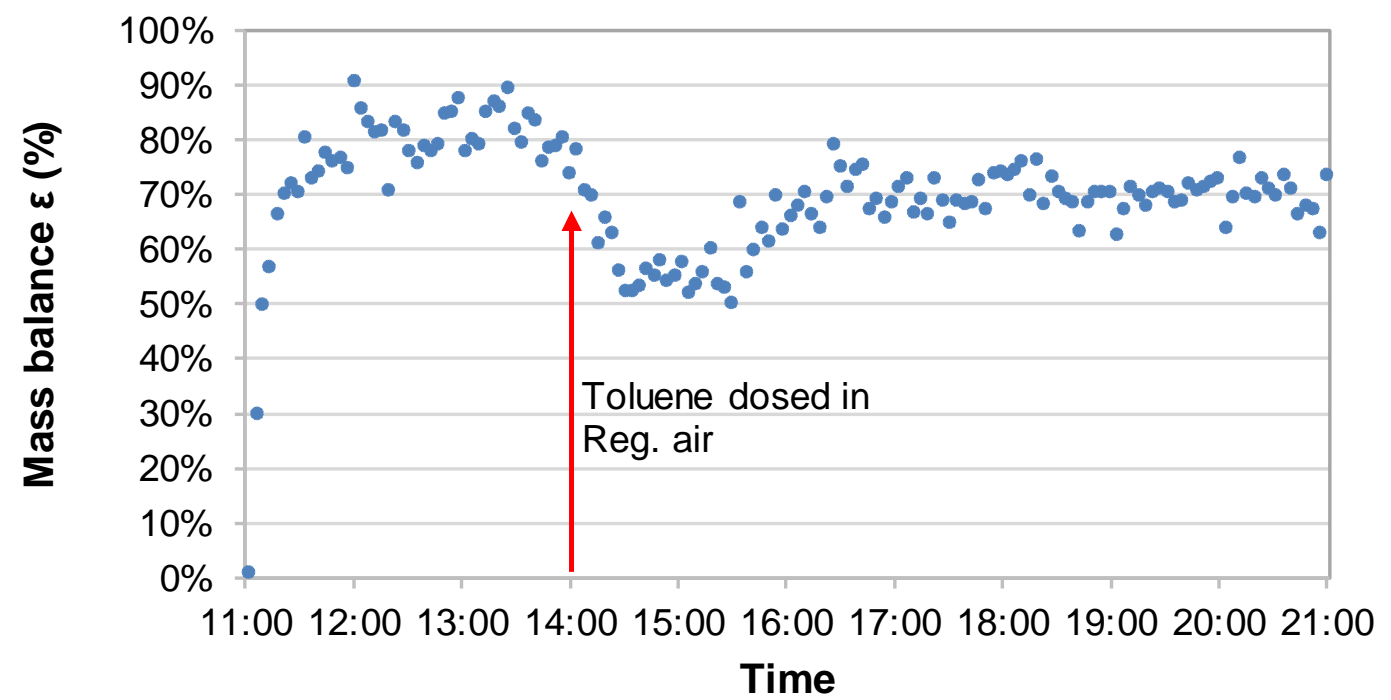

Fig. 9 Mass balance calculated during the process of toluene removal at the regeneration air temperature of $50^{\circ} \mathrm{C}$

From the results of energy performance analysis of the CAHP, the energy is significantly saved with CAHP using exhaust air for regeneration compared with CAHP using outdoor air for regeneration, regardless of the degradation of indoor air quality. However, the degradation of indoor air quality is only due to $10 \sim 20 \%$ lower of pollutants removal capability of CAHP, which is predicted that this may not be easily perceived by humans in the actual indoor environment. Of course, the accurate result should be obtained by conducting another perceived indoor air quality evaluation by a panel of human subjects. This is worth further studied. If the concentration of pollutants in the indoor air is required to be controlled, using exhaust air for regeneration of CAHP is not recommended, since supplemented outdoor air and other possible solutions to maintain the indoor air quality increases the energy consumed of CAHP, which is not acceptable from the energy point of view. Moreover, it will make the indoor air quality more difficult to be controlled. In this case, CAHP using outdoor air for regeneration is recommended.

\section{Conclusion}

In this study, the effect of polluted regeneration air on the air cleaning performance of CAHP system was examined experimentally. The polluted regeneration air reduced the pollutants removal capability of the CAHP, which led to a reduction of approx. $10 \%$ in air 
cleaning efficiency. The reduction of air purification capability of CAHP were taken place either toluene or acetone determined as pollutant. In view of toluene and acetone representing the properties of most polar and nonpolar, water-soluble and non-water-soluble compounds, it can be inferred that the regeneration air polluted by VOCs has an impact on the pollutants removal efficiency of CAHP. Operation of CAHP at low regeneration air temperature could further worsened the air purification performance. If the pollutant in the regeneration air was different from the target pollutant contained in the process air, CAHP had a very similar removal capability for target pollutant compared with when the same target pollutant in the regeneration air.

The energy consumption of CAHP using exhaust air for regeneration was numerically simulated and analysed, compared with CAHP using outdoor air for regeneration. Increasing the intake of outdoor air for the room could maintain the same concentration of pollutants in the indoor air as that when using outdoor air for regeneration but increase the energy consumption of the CAHP. If regardless of the degradation of indoor air quality when using exhaust air for regeneration, the energy of the CAHP would be significantly saved. Since the degradation of indoor air quality caused by the reduction of air cleaning efficiency of the CAHP is not so significant that it is predicted to be not easily perceived by the humans, it is recommended that the CAHP used as an air conditioner should be operated with exhaust air for regeneration. However, this should be further verified by the evaluation of human subjects.

\section{Acknowledgement}

This study is financially supported by National Key R\&D Program of China (2017YFC0211500). Great thanks also give to the financial support by EU Climate KIC pathfinder project - CAHP, BjarneSaxhof foundation.

\section{References}

[1] Subramanyam N, Maiya MP, Murthy SS. Application of desiccant wheel to control humidity in air-conditioning systems. Applied Thermal Engineering, 2004, 24: 27772788.

[2] La D, Dai YJ, Li Y, Wang RZ, Ge TS. Technical development of rotarydesiccant 
dehumidification and air conditioning: a review. Renewable and Sustainable Energy Reviews, 2010, 14: 130-147.

[3] Jia CX, Dai YJ, Wu JY, Wang RZ. Analysis on a hybrid desiccant air conditioning systems. Applied Thermal Engineering, 2006, 26: 2393-2400.

[4] Angrisani G, Minichiello F, Roselli C, Sasso M. Experimental investigation to optimise a desiccant HVAC system coupled to a small size cogenerator. Applied Thermal Engineering, 2011, 31: 506-512.

[5] La D, Dai YJ, Li Y, Ge TS, Wang RZ. Case study and theoretical analysis of a solar driven two-stage rotary desiccant cooling system assisted by vapor compression air-conditioning. Solar Energy, 2011, 85:2997-3009.

[6] Angrisani G, Roselli C, Sasso M. Experimental assessment of the energy performance of a hybrid desiccant cooling system and comparison with other air-conditioning technologies. Applied Energy, 2015, 138:533-545.

[7] Han X, Zhang X. Hybrid Desiccant Cooling System Using Condensing Heat as the Regeneration Source. Part II: Energy Saving Potential. Advanced Materials Research, 2011, (383-390):6431-6435.

[8] Jani D, Mishra M, Sahoo P. Performance studies of hybrid solid desiccant-vapor compression air-conditioning system for hot and humid climates. Energy and Buildings, 2015,102:284-92.

[9] Sheng Y, Zhang YF, Deng N, Fang L, Nie JZ, Ma LJ. Experimental analysis on performance of high temperature heat pump and desiccant wheel system. Energy and buildings, 2013, 66: 505-513.

[10] Sheng Y, Zhang YF, Zhang G. Simulation and energy saving analysis of high temperature heat pump coupling to desiccant wheel air conditioning system. Energy, 2015, 83: 583-596.

[11] Nie JZ, Fang L, Zhang G, Sheng Y, Kong XR, Zhang YF, Olesen BW. Theoretical study on volatile organic compound removal and energy performance of a novel heat pump assisted solid desiccant cooling system. Building and environment, 2015, 85: 233-242.

[12] Nie JZ, Fang L, Olesen BW. Experimental evaluation on energy performance of innovative clean air heat pump for indoor environment control in summer and winter seasons. Energy and buildings, 2014, 84: 641-650.

[13] Hines AL, Ghosh TK, Loyalka SK, Warder RC. Investigation of Co-Sorption of Gases and 
Vapors as a Means to Enhance Indoor Air Quality - Phase 2: A Summary of Pollutant Removal Capabilities of Solid and Liquid Desiccants from Indoor Air, Chicago, Report of Gas Research Institute: GRI-92/0157, 1993.

[14] Popescu M, Ghosh TK. Dehumidification and simultaneous removal of selected pollutants from indoor air by a desiccant wheel using a $1 \mathrm{M}$ type desiccant. Jounal of Solar Energy Engineering, 1999, 121: 1-13.

[15] Fang L, Zhang G, Wisthaler A. Desiccant wheels as gas-phase absorption (GPA) air cleaners: evaluation by PTR-MS and sensory assessment. Indoor Air, 2008, 18 (5): 375385.

[16] Sheng Y, Fang L, Nie JZ. Experimental analysis of indoor air quality improvement achieved by using a Clean-Air Heat Pump (CAHP) air-cleaner in a ventilation system. Building and environment, 2017, 122: 343-353.

[17] Zhang XJ, Dai YJ, Wang RZ. A simulation study of heat and mass transfer in a honeycombed rotary desiccant dehumidifier. Applied thermal engineering, 2003, 23:989-1003.

[18] Jia CX, Dai YJ, Wu JY, Wang RZ. Use of compound desiccant to develop high performance desiccant cooling system. International Journal of refrigeration, 2007, 30: 345-353.

[19] Pennington NA. Humidity changer for air conditioning. USA, Patent No. 2,700,537; 1955.

[20] Collier RK, Cohen BM. An analytical examination of methods for improving the performance of desiccant cooling systems. Journal of Solar Energy Engineering, 1991, 113(3):151-63.

[21] Worek WM, Zheng W, Belding WA, Novosel D, Holeman WD. Simulation of advanced gas-fired desiccant systems. ASHRAE Transactions, 1991, 97(2): 609-14.

[22] Ge TS, Li Y, Wang RZ, Dai YJ. Experimental study on a two-stage rotary desiccant cooling system. International Journal of Refrigeration, 2009, 32(3): 498-508.

[23] Kolarik J, Toftum J, Kabrhel M, Jordan F, Geiss O, Kabele K. Field measurements of perceived air quality and concentration of volatile organic compounds in four offices of the university building. Indoor and built environment, 2015, 24(8): 1048-1058.

[24] Sun YX, Fang L, Wyon DP, Wisthaler A, Lagercrantz L, Tejsen PS. Experimental research on photcatalytic oxidation air purification technology applied to aircraft cabins. Building and environment, 2008, 43: 258-268. 
[25] WHO, Air quality guidelines for Europe. $2^{\text {nd }}$ edition, WHO regional publications, European Series No. 91, 2000.

[26] Angrisani G, Minichiello F, Roselli C, Sasso M. Experimental analysis on the dehumidification and thermal performance of a desiccant wheel. Applied Energy, 2012, 92: $563-572$.

[27] CEN. TC156, Guideline for using indoor environmental input parameters for the design and assessment of energy performance of buildings, 2016. EN 16798-2 TR, European Committee for Standardization. 


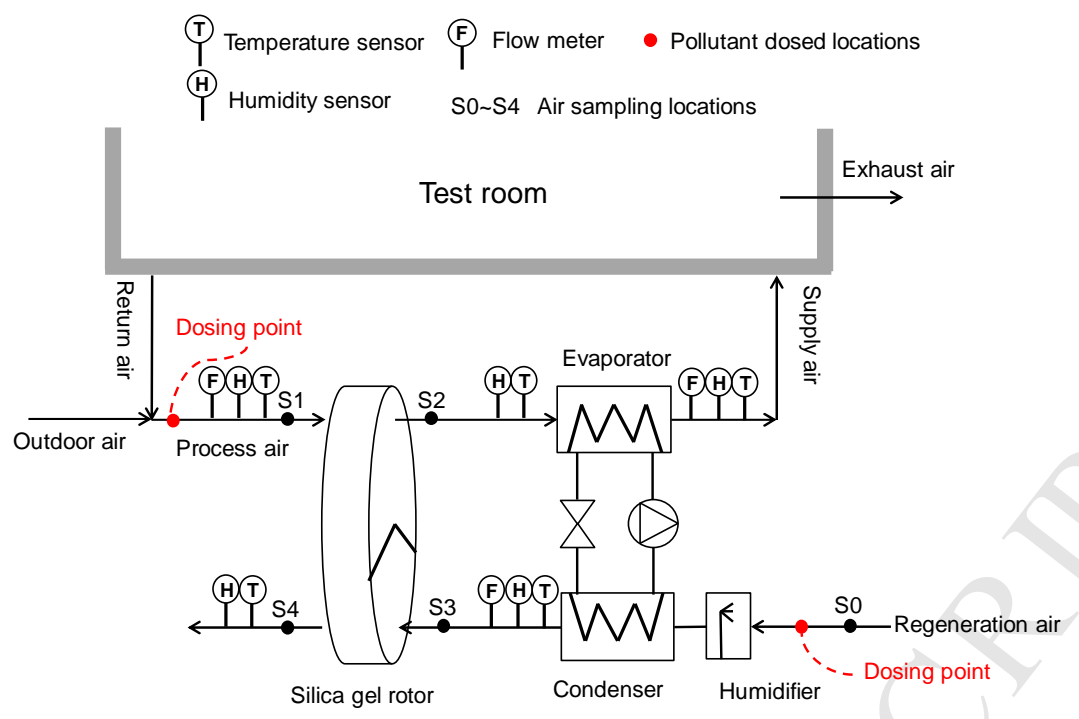

Fig. 1 Experimental facility

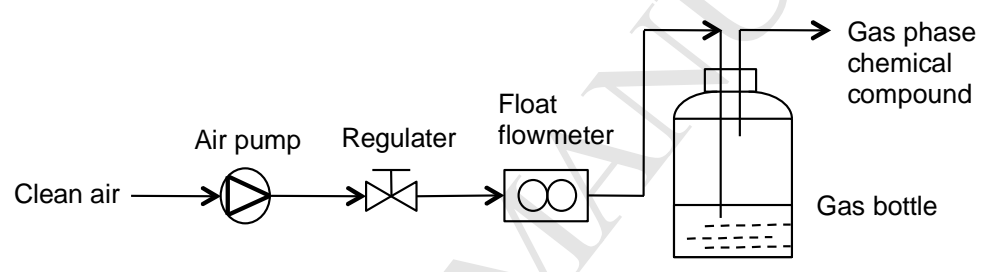

Fig. 2 Schematic diagram of chemicals dosed

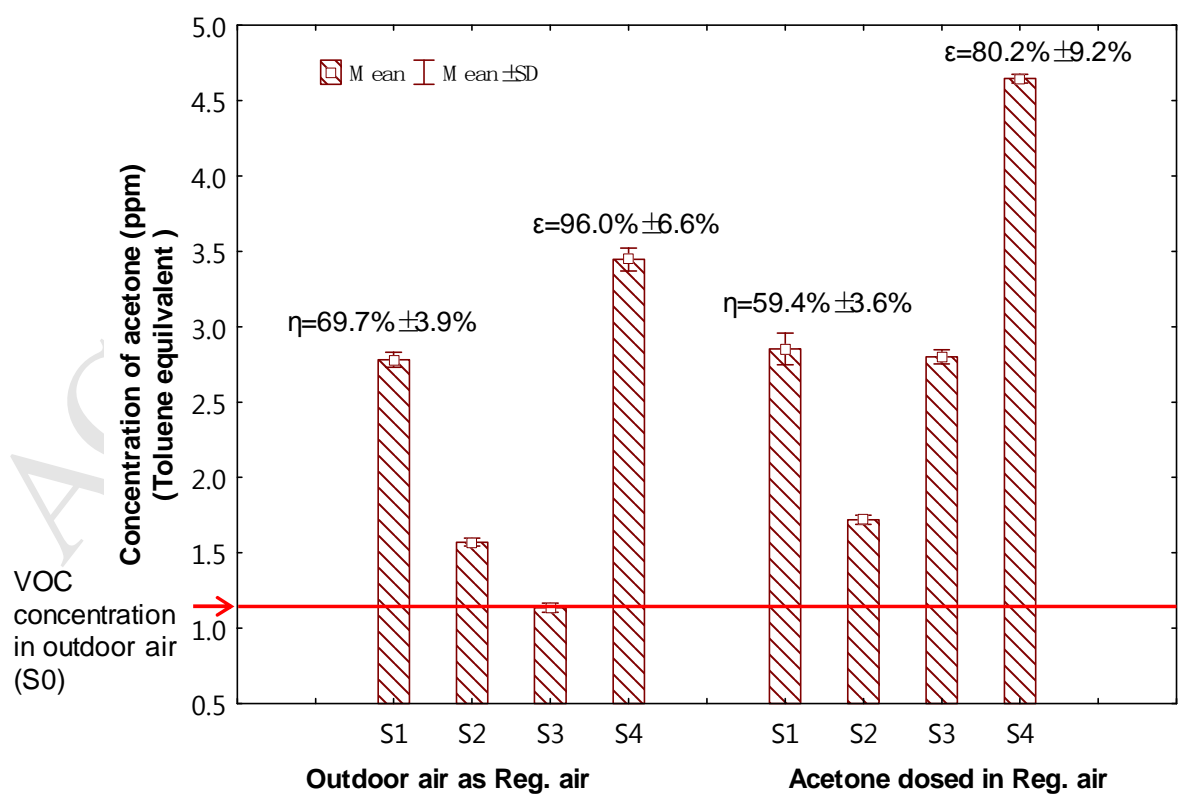

Fig. 3 Average concentration of acetone upstream and downstream of the process 
and regeneration side when $T_{\text {reg }}=60^{\circ} \mathrm{C}$

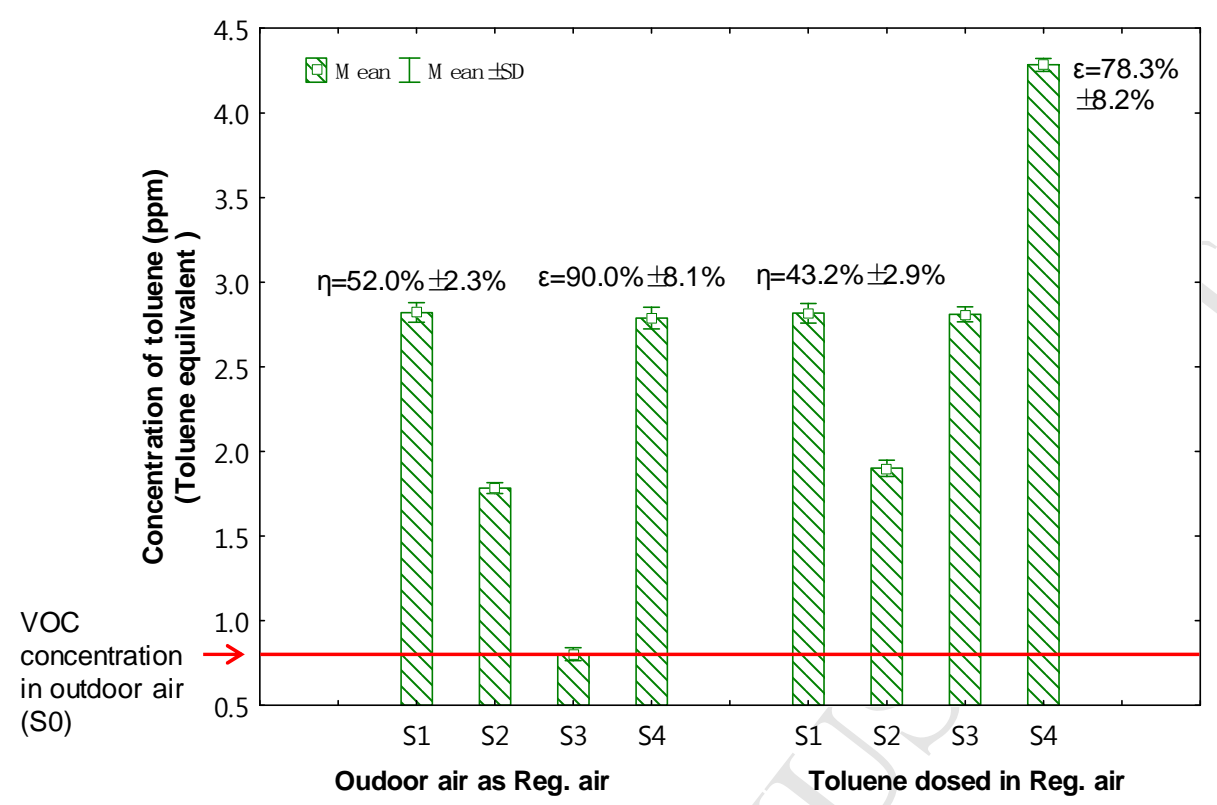

Fig. 4 Average concentration of toluene upstream and downstream of the process and regeneration side when $\mathrm{T}_{\text {reg }}=60^{\circ} \mathrm{C}$

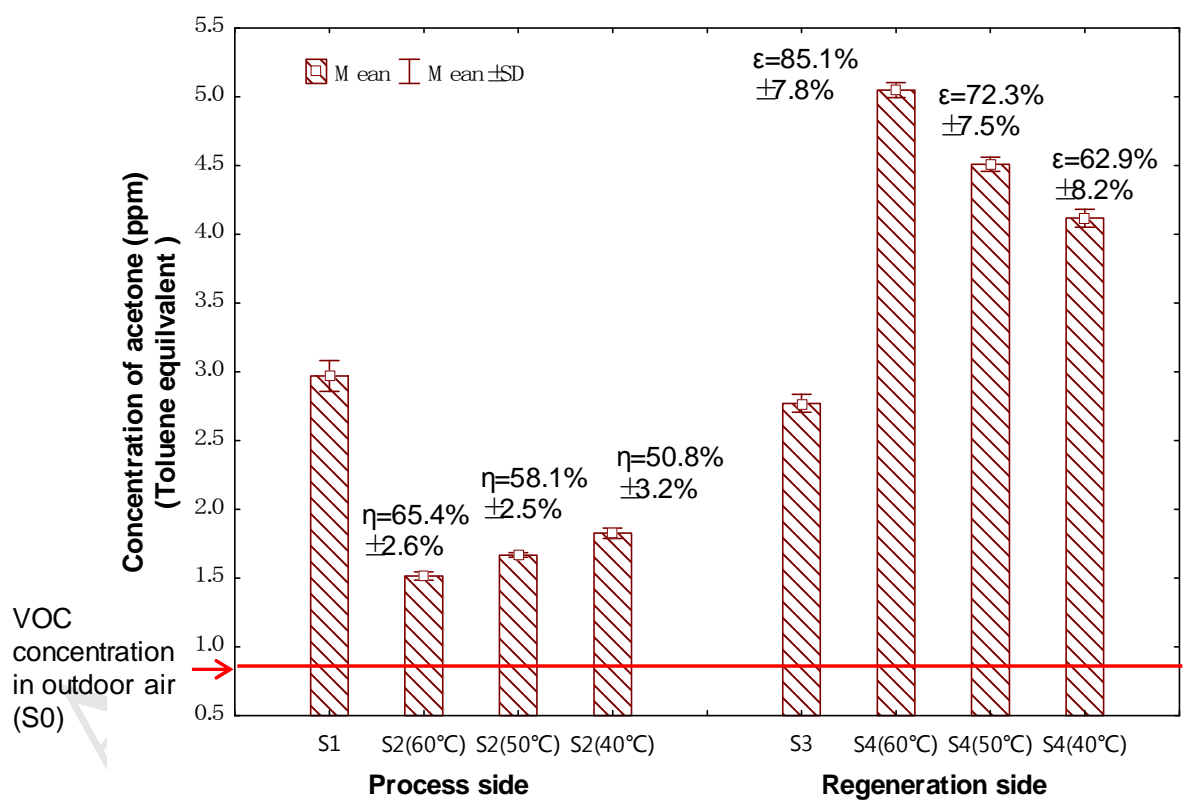

Fig.5 Average concentration of acetone upstream and downstream of the process and regeneration side at the regeneration temperature of $40,50,60^{\circ} \mathrm{C}$ 


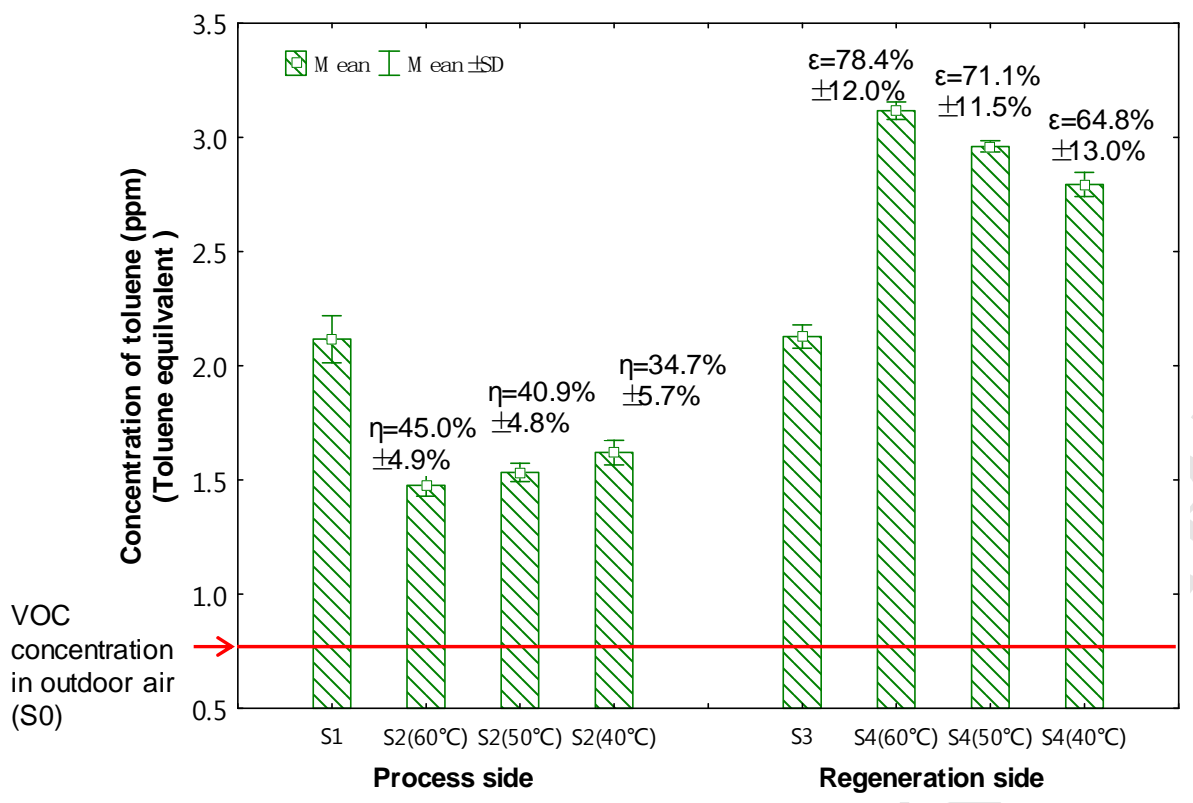

Fig.6 Average concentration of toluene upstream and downstream of the process and regeneration side at the regeneration temperature of $40,50,60^{\circ} \mathrm{C}$

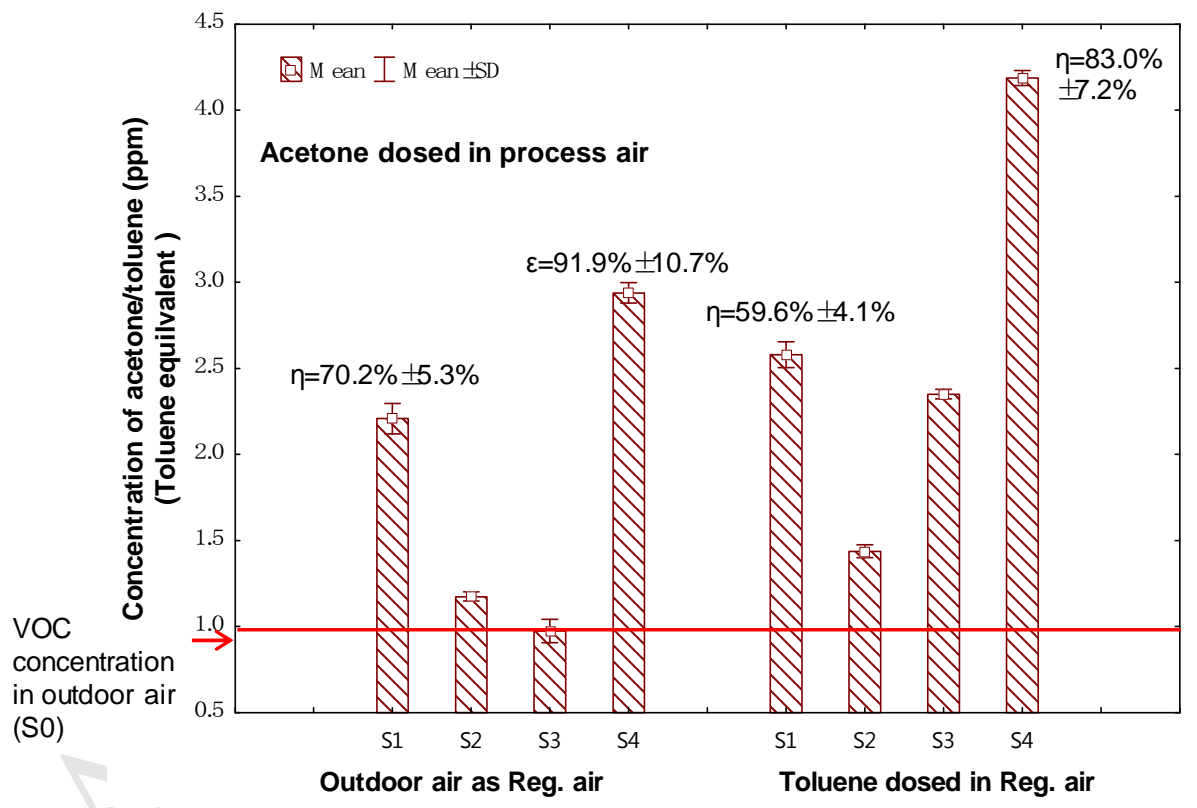

Fig. 7 Average concentration of acetone/toluene when toluene determined as pollutant in the regeneration air at $T_{\text {reg }}=60^{\circ} \mathrm{C}$ 


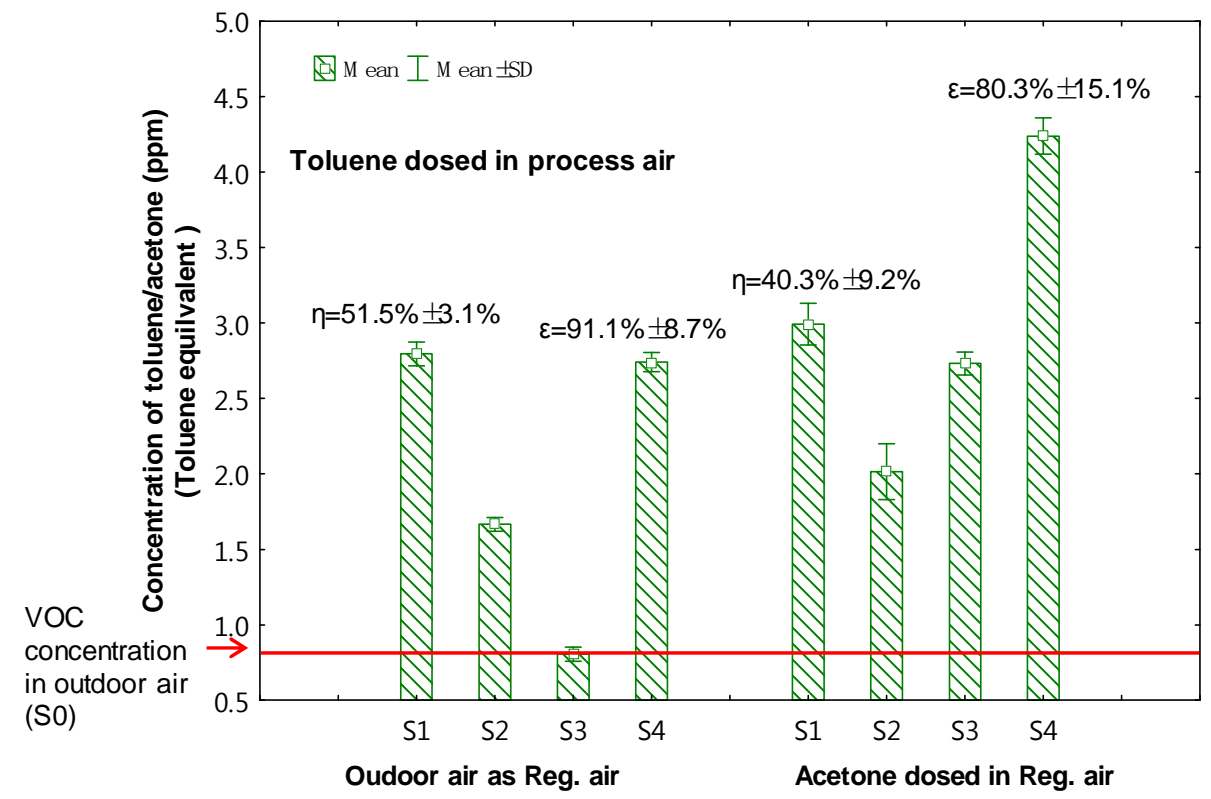

Fig. 8 Average concentration of toluene/acetone when acetone determined as pollutant in the regeneration air at $\mathrm{T}_{\text {reg }}=60^{\circ} \mathrm{C}$

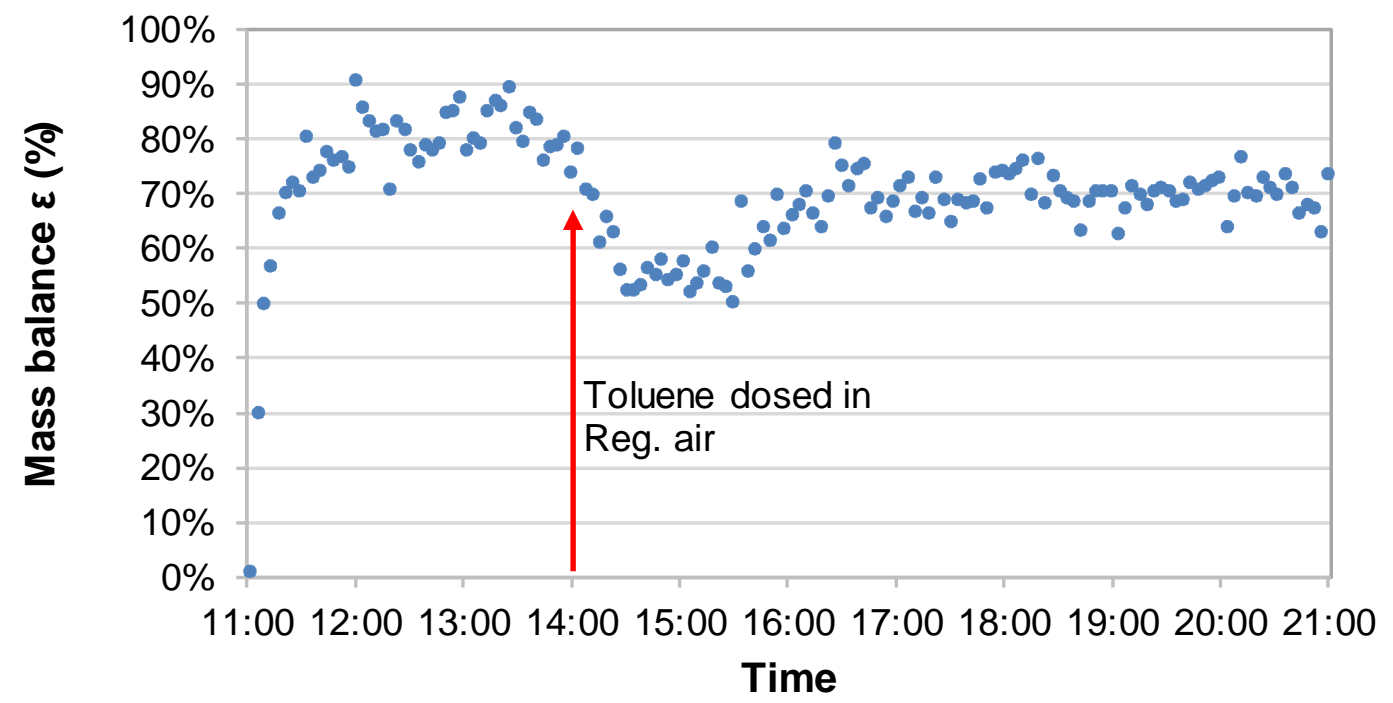

Fig. 9 Mass balance calculated during the process of toluene removal at the regeneration air temperature of $50^{\circ} \mathrm{C}$ 


\section{Highlights}

- $\quad$ Air cleaning efficiency of CAHP was reduced by $10 \%$ using polluted air for regeneration.

- Higher regeneration air temperature, higher air cleaning efficiency of CAHP.

- Energy conservation of CAHP was obvious using exhaust air for regeneration regardless

of degradation of indoor air quality.

- Increasing outdoor air can maintain indoor air quality but consume more energy when CAHP using exhaust air for regeneration. 